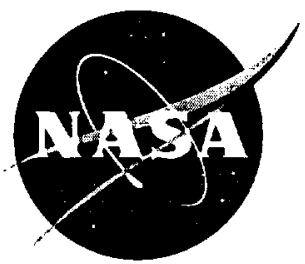

\title{
Wind-Tunnel Investigations of Blunt-Body Drag Reduction Using Forebody Surface Roughness
}

Stephen A. Whitmore

NASA Dryden Flight Research Center

Edwards, California

Stephanie Sprague

University of Kansas

Lawrence, Kansas

Jonathan W. Naughton

University of Wyoming

Laramie, Wyoming 


\section{The NASA STI Program Office...in Profile}

Since its founding, NASA has been dedicated to the advancement of aeronautics and space science. The NASA Scientific and Technical Information (STI) Program Office plays a key part in helping NASA maintain this important role.

The NASA STI Program Office is operated by Langley Research Center, the lead center for NASA's scientific and technical information. The NASA STI Program Office provides access to the NASA STI Database, the largest collection of aeronautical and space science STI in the world. The Program Office is also NASA's institutional mechanism for disseminating the results of its research and development activities. These results are published by NASA in the NASA STI Report Series, which includes the following report types:

- TECHNICAL PUBLICATION. Reports of completed research or a major significant phase of research that present the results of NASA programs and include extensive data or theoretical analysis. Includes compilations of significant scientific and technical data and information deemed to be of continuing reference value. NASA's counterpart of peer-reviewed formal professional papers but has less stringent limitations on manuscript length and extent of graphic presentations.

- TECHNICAL MEMORANDUM. Scientific and technical findings that are preliminary or of specialized interest, e.g., quick release reports, working papers, and bibliographies that contain minimal annotation. Does not contain extensive analysis.

- CONTRACTOR REPORT. Scientific and technical findings by NASA-sponsored contractors and grantees.
- CONFERENCE PUBLICATION. Collected papers from scientific and technical conferences, symposia, seminars, or other meetings sponsored or cosponsored by NASA.

- SPECIAL PUBLICATION. Scientific, technical, or historical information from NASA programs, projects, and mission, often concerned with subjects having substantial public interest.

- TECHNICAL TRANSLATION. Englishlanguage translations of foreign scientific and technical material pertinent to NASA's mission.

Specialized services that complement the STI Program Office's diverse offerings include creating custom thesauri, building customized databases, organizing and publishing research results...even providing videos.

For more information about the NASA STI Program Office, see the following:

- Access the NASA STI Program Home Page at http://www.sti.nasa.gov

- E-mail your question via the Internet to help@sti.nasa.gov

- Fax your question to the NASA Access Help Desk at (301) 621-0134

- Telephone the NASA Access Help Desk at (301) 621-0390

- Write to: NASA Access Help Desk

NASA Center for AeroSpace Information 7121 Standard Drive Hanover, MD 21076-1320 
NASA/TM-2001-210390

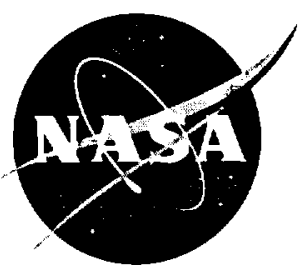

\section{Wind-Tunnel Investigations of Blunt-Body Drag Reduction Using Forebody Surface Roughness}

Stephen A. Whitmore

NASA Dryden Flight Research Center

Edwards, California

Stephanie Sprague

University of Kansas

Lawrence, Kansas

Jonathan W. Naughton

University of Wyoming

Laramie Wyoming

National Aeronautics and

Space Administration

Dryden Flight Research Center

Edwards, California 93523-0273 


\section{NOTICE}

Use of trade names or names of manufacturers in this document does not constitute an official endorsement of such products or manufacturers, either expressed or implied, by the National Aeronautics and Space Administration.

Available from the following:

NASA Center for AeroSpace Information (CASI) 7121 Standard Drive Hanover, MD 21076-1320 (301) 621-0390
National Technical Information Service (NTIS) 5285 Port Royal Road Springfield, VA 22161-2171

(703) 487-4650 


\title{
WIND-TUNNEL INVESTIGATIONS OF BLUNT-BODY DRAG REDUCTION USING FOREBODY SURFACE ROUGHNESS
}

\author{
Stephen A. Whitmore* \\ NASA Dryden Flight Research Center \\ Edwards, California \\ Stephanie Sprague ${ }^{\dagger}$ \\ University of Kansas \\ Lawrence, Kansas \\ Jonathan W. Naughton ${ }^{\ddagger}$ \\ University of Wyoming \\ Laramie. Wyoming
}

\begin{abstract}
This paper presents results of wind-tunnel tests that demonstrate a novel drag reduction technique for bluntbased vehicles. For these tests. the forebody roughness of a blunt-based model was modified using micromachined surface overlays. As forebody roughness increases, boundary layer at the model aft thickens and reduces the shearing effect of external flow on the separated flow behind the base region. resulting in reduced base drag. For vehicle configurations with large base drag, existing data predict that a small increment in forebody friction drag will result in a relatively large decrease in base drag. If the added increment in forebody skin drag is optimized with respect 10 base drag. reducing the total drag of the configuration is possible. The wind-tunnel tests results conclusively demonstrate the existence of a forebody drag-base drag optimal point. The data demonstrate that the base drag coefficient corresponding to the drag minimum lies between 0.225 and 0.275 , referenced to the base area. Most importantly, the data show a drag

\footnotetext{
* Aerospace Enguneer. Associate Fellow. AlAA.

†'Sudent Intem. Department of Acrospace Engineering. Student Member. AlAA.

${ }_{\ddagger}$ Professor. Department of Mechanical Engineering. Senior
for. AlaA. Member. AIAA.

Copyright 2001 by the American Institute of Aeronautics and Title 17, II.S. Code. The U.S. Govemment has a royalty-free license to exercise all rights under the copyright claimed herein for Governmental purposes. All other rights are reserved by the copyright owner
} Astronautics. Inc. No copyright is asserted in the United States under
\end{abstract}

reduction of approximately 15 percent when the drag optimum is reached. When this drag reduction is scaled to the X-33 base area, drag savings approaching $45,000 \mathrm{~N}(10,000 \mathrm{lbf})$ can be realized.

\section{Nomenclature}

\section{Acronyms}

CFD computational fluid dynamics

LASRE Linear Aerospike SR-71 Experiment

Symbols

A slope parameter

$a_{0}, a_{1}, a_{2}, a_{3}$ forebody pressure distribution curve-fit coefficients

B law-of-the-wake bias parameter

$b$ model span, $\mathrm{cm}$

$b_{0}, b_{2}, b_{4} \quad$ base pressure distribution curve-fit coefficients

C intercept parameter

$C_{D} \quad$ drag coefficient

$C_{D_{\text {buse }}} \quad$ base pressure drag coefficient

$C_{D_{\text {furechody }}}$

$C_{D_{0}}$ forebody pressure drag coefficient

$C_{F} \quad$ "viscous" forebody drag coefficient

$c_{f} \quad$ local skin-friction coefficient 


\begin{tabular}{|c|c|c|c|}
\hline$C_{p}$ & pressure coefficient & $x$ & axial location within wind tunnel, $\mathrm{cm}$ \\
\hline$C_{p_{b i s e}}$ & average base pressure coefficient & $x_{i}$ & $\begin{array}{l}i^{\text {th }} \text { scalar component of independent } \\
\text { variable vector }\end{array}$ \\
\hline$C_{p_{\text {forebouls }}}$ & average forebody pressure coefficient & & \\
\hline $\begin{array}{l}D^{\prime} \\
d P\end{array}$ & section drag, $\mathrm{N} / \mathrm{m}$ & $y$ & $\begin{array}{l}\text { lateral coordinate (for wake, boundary } \\
\text { layer, or base area) } \mathrm{cm}\end{array}$ \\
\hline$\frac{d e}{d x}$ & $\begin{array}{l}\text { longitudinal pressure gradient on } \\
\text { model, } \mathrm{kPa} / \mathrm{m}\end{array}$ & $y^{+}$ & $\begin{array}{l}\text { nondimensional boundary-layer } \\
\text { coordinate }\end{array}$ \\
\hline$\frac{d \theta}{d x}$ & $\begin{array}{l}\text { longitudinal gradient of the boundary- } \\
\text { layer momentum thickness }\end{array}$ & $Z$ & output vector \\
\hline $\mathrm{E}[]$. & expectation operator & $Z^{(\text {meas })}$ & measurement vector \\
\hline$H$ & $\begin{array}{l}\text { wake or boundary-layer shape parameter, } \\
H=\delta / \theta\end{array}$ & $z_{i}$ & $\begin{array}{l}i^{\text {th }} \text { scalar component of measurement } \\
\text { vector }\end{array}$ \\
\hline$h_{\text {base }}$ & base height, $\mathrm{cm}$ & $\beta$ & Clauser pressure gradient parameter \\
\hline$i$ & measurement index & $\Gamma$ & friction velocity \\
\hline$L$ & model length, $\mathrm{cm}$ & $\Delta\left[\frac{\hat{u}(y)}{U_{e}}\right]$ & $\begin{array}{l}\text { local curve-fit error for velocity } \\
\text { distribution }\end{array}$ \\
\hline $\begin{array}{l}N_{\text {trials }} \\
n\end{array}$ & $\begin{array}{l}\text { number of repeated pressure scans } \\
\text { number of data points }\end{array}$ & $\Delta \theta$ & $\begin{array}{l}\text { first variation of momentum } \\
\text { thickness, } \mathrm{cm}\end{array}$ \\
\hline$p$ & local static pressure, $\mathrm{kPa}$ & $\nabla_{\delta}$ & gradient with respect to $\delta$ \\
\hline 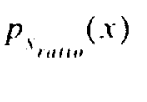 & $\begin{array}{l}\text { free-stream static pressure ratio in wind } \\
\text { tunnel }\end{array}$ & $\delta$ & $\begin{array}{l}\text { wake half-width, local boundary-layer } \\
\text { thickness, cm }\end{array}$ \\
\hline$p_{\infty}$ & $\begin{array}{l}\text { free-stream static pressure ahead of } \\
\text { wind-tunnel model, } \mathrm{kPa}\end{array}$ & $\delta^{(0)}$ & $\begin{array}{l}\text { initial estimate of wake half-width or } \\
\text { boundary-layer thickness }\end{array}$ \\
\hline $\bar{q}$ & dynamic pressure, $k P a$ & $\delta^{*}$ & boundary-layer displacement \\
\hline $\bar{q}_{\text {ratio }}(x)$ & dynamic pressure ratio in wind tunnel & & thickness, cm \\
\hline $\bar{q}_{\infty}$ & $\begin{array}{l}\text { free-stream dynamic pressure ahead of } \\
\text { wind-tunnel model, } \mathrm{kPa}\end{array}$ & $\begin{array}{l}\delta^{*} \\
\zeta\end{array}$ & $\begin{array}{l}\text { wake displacement thickness, } \mathrm{cm} \\
\text { dummy integration variable }\end{array}$ \\
\hline $\mathrm{Re}_{L}$ & $\begin{array}{l}\text { Reynolds number based on model } \\
\text { length } L\end{array}$ & $\theta$ & forebody surface incidence angle, deg \\
\hline $\operatorname{Re}_{x}$ & $\begin{array}{l}\text { Reynolds number based on local axial } \\
\text { coordinate } x\end{array}$ & $\theta_{\infty}$ & free-stream momentum thickness, $\mathrm{cm}$ \\
\hline$r$ & leading-edge radius, $\mathrm{cm}$ & $\kappa$ & law-of-the-wake slope parameter \\
\hline$U_{e}$ & $\begin{array}{l}\text { velocity at the edge of the wake or } \\
\text { boundary layer, } \mathrm{m} / \mathrm{sec}\end{array}$ & $\kappa_{s}$ & $\begin{array}{l}\text { equivalent sand-grain roughness of } \\
\text { surface, } \mathrm{cm}\end{array}$ \\
\hline \multirow[t]{2}{*}{$U_{\infty}$} & \multirow{2}{*}{$\begin{array}{l}\text { free-stream velocity ahead of the } \\
\text { wind-tunnel model, } \mathrm{m} / \mathrm{sec}\end{array}$} & $\kappa-\varepsilon$ & energy dissipation \\
\hline & & $\Lambda$ & Dirac delta function \\
\hline$"$ min & $\begin{array}{l}\text { minimum velocity in wake velocity } \\
\text { profile, } \mathrm{m} / \mathrm{sec}\end{array}$ & $\lambda$ & roughness overlay "land" thickness, cm \\
\hline \multirow[t]{2}{*}{$u(y)$} & local velocity distribution (in wake or & $\mu$ & sample mean \\
\hline & boundary layer), $\mathrm{m} / \mathrm{sec}$ & $\xi$ & dummy integration variable \\
\hline$u^{+}$ & nondimensional boundary-layer velocity & $\Pi$ & wake parameter \\
\hline$X$ & independent variable vector & $\rho$ & air density, $\mathrm{kg} / \mathrm{cm}^{3}$ \\
\hline
\end{tabular}




$$
\begin{aligned}
& \Sigma \quad \text { roughness overlay slot thickness, } \mathrm{cm} \\
& \sigma_{\text {base }}{ }^{2} \quad \text { curve-fit squared error for base ports } \\
& \sigma_{\text {side }}{ }^{2} \quad \text { curve-fit squared error for side ports } \\
& \sigma_{\theta}{ }^{2} \quad \text { sample variance for pressure port } \\
& \text { incidence angle } \theta \\
& \tau \text { roughness overlay shim thickness, } \mathrm{cm} \\
& \Psi^{2} C_{D_{\text {buse }}} \quad \begin{array}{l}
\text { mean-square error in base drag } \\
\text { coefficient estimate }
\end{array} \\
& \Psi^{2} C_{D_{\text {forehody }}} \text { mean-square error in forebody pressure } \\
& \Psi^{2} C_{D_{0}} \quad \text { mean-square error in viscous forebody } \\
& \text { drag coefficient estimate } \\
& \Psi^{2} C_{F} \quad \text { mean-square error in viscous forebody } \\
& \Psi_{\Delta \theta}^{2} \quad \text { mean-square error in momentum } \\
& \text { thickness estimate, } \mathrm{cm}^{2} \\
& \Psi^{2}{ }_{\Delta u / U_{e}} \quad \text { mean-square error in velocity profile } \\
& \text { curve fit. } \mathrm{cm}^{2}
\end{aligned}
$$

\section{Superscripts, Subscripts, and Mathematical Operators}

$i \quad$ measurement index

$j \quad$ pressure port index

estimated parameter

$\Delta \quad$ variational operator

T vector transpose

\section{Introduction}

Designs advocated for the current generation of reusable launch or space-access vehicles are derived from variations of the original lifting-body concept. ${ }^{1}$ For many reasons, these designs all have large base areas compared with those of conventional aircraft. For example, the large base areas of the $\mathrm{X}-33$ and Venture Star configurations are required to accommodate the aerospike rocket engines. The base area is highly separated, resulting in large negative base pressure coefficients. Because of the large base-to-wetted-area ratios of these vehicles, the base drag comprises the majority of the overall vehicle drag. The resulting low lift-to-drag ratios result in very steep approach glide slopes. These steep approach angles present difficult energy management tasks for autonomous reentry systems. Any decrease in base drag potentially can significantly improve the overall vehicle performance and make the autonomous reentry and landing task less difficult.

An early body of experimental work conducted in the late $1950^{\circ}$ s and early 1960's by Hoerner ${ }^{2}$ offers a potential solution to the reusable launch vehicle (RLV) base drag problem. For blunt-based objects with heavily separated base areas, a correlation between the base pressure drag and the "viscous" forebody drag has been demonstrated. This paper presents the results of a series of wind-tunnel experiments that exploit this forebodyto-base drag relationship to reduce the overall drag of a simple blunt-based configuration by adding precise levels of roughness to the forebody.

\section{Background}

For blunt-based objects whose base areas are heavily separated, a clear relationship between base drag and the viscous forebody drag has been demonstrated by Hoerner. ${ }^{2}$ In this paper, the viscous forebody drag is defined as the axial projection of the integral of all viscous forces acting on the vehicle forebody. These viscous forces include surface skin friction, frictional effects of forebody flow separation, and parasite drag. Axial forces resulting from the forebody pressure distribution are considered separately from the viscous forebody drag in this paper.

Figure 1 shows subsonic drag data taken from Hoerner for two- and three-dimensional projectiles. The three-dimensional curve fit of the data was originally published by Hoerner. ${ }^{2}$ The two-dimensional curve fit is a new fit of Hoerner's original data. The authors of this paper believe that this new fit is a better representation of the base drag data.

An important feature is the trend for decreasing base drag as the viscous forebody drag increases (fig. 1). This base drag reduction is a result of boundary-layer effects at the vehicle base. The surface boundary layer acts as an insulator between the external flow and the separated air behind the base. As the forebody drag increases, the boundary-layer thickness at the forebody aft also increases. This increase reduces the effectiveness of the "jet pump" caused by the shearing of the external flow on the separated flow behind the base region.

Vehicle configurations with large base drag coefficients lie on the steep portion of Hoerner's curve, where a small increment in the forebody friction drag should result in a relatively large decrease in the base drag. Conceptually, if the added increment in viscous forebody drag is optimized with respect to the base 
drag, then reducing the overall drag of the configuration may be possible. Figure 2 shows this drag optimization, based on curve fits of Hoerner's data. These data clearly illustrate the concept of the "drag bucket."

Another important feature of the data shown in figures 1 and 2 is that for the same viscous forebody drag, twodimensional objects tend to have a significantly larger base drag than three-dimensional objects. These drag differences result from periodic shedding in the base region where a von Karman vortex street structure $e^{3,4}$ of evenly spaced vortices of alternating strengths sets up within the wake. In general, the base flow around three-dimensional objects is characterized by verybroadband (frequency) flow disturbances; the periodic flow phenomenon is far less pronounced than for twodimensional objects. The base pressure under nonperiodic (three-dimensional) flow conditions is considerably higher (equating to lower base drag) than under similar conditions in a periodic (two-dimensional) flow.

The ramifications of this two-dimensional-threedimensional base drag difference become extremely important when one considers full-scale, high-Reynolds number flight vehicles. Saltzman, et al. ${ }^{5}$ have compiled subsonic drag data from vehicles configured for hypersonic flight. This compendium includes flight data for the X-15, M2-F1, M2-F3, $X-24 A$, and X-24B vehicles; the Space Shuttle; and the Linear Aerospike SR-71 Experiment (LASRE). These data are compared to the two- and three-dimensional mathematical models derived from Hoerner's data (fig. 3). The full-scale flight data clearly agree more closely with the two-dimensional curve than the threedimensional one. For full-scale configurations, the flow appears to be locally two-dimensional and allows the trailing vortex street to become well-established. Figure 4 shows direct visual proof of this assertion, as a periodic vortex structure is clearly visible trailing behind the $\mathrm{M} 2-\mathrm{F} 1$ vehicle.

The data shown in figures $1-3$ imply that large-scale, blunt-based vehicles are quasi-two-dimensional, and configurations with a base drag coefficient greater than approximately 0.30 (referenced to the base area) will lie on the left side of Hoerner's curve. These configurations may be considered to be suboptimal with respect to the viscous forebody drag coefficient. Incrementally increasing the viscous forebody drag theoretically should lower the overall drag of the configuration.

\section{The Linear Aerospike SR-71 Experiment}

Flight test results from the LASRE drag reduction experiment ${ }^{6}$ provide some incomplete validation of the above hypothesis. The LASRE was a flight test of an approximately 20-percent half-span model of an X-33 forebody model mounted on top of the NASA SR-71 aircraft. The LASRE sought to reduce base drag by adding a small amount of surface roughness to the model forebody. The model was instrumented with load cells that allowed a six-degree-of-freedom measurement of forces and moments, and with surface pressure ports that allowed the model forebody pressure and base drag to be numerically integrated.

The LASRE verified that the base drag was reduced by as much as 15 percent; unfortunately, the overall drag of the configuration was not reduced. The methods for applying the forebody sand-grain roughness were believed to be too crude to achieve an overall drag reduction. Further tests under a more controlled flow environment were clearly required.

\section{Wind-Tunnel Tests}

A series of low-speed, two-dimensional, wind-tunnel tests was conducted to study the potential for minimizing the total configuration drag using surface roughness increments. In these tests, a leading-edge cylinder with a blunt afterbody was tested. The fullscale flight data (figs. 3-4) demonstrate that the results of the two-dimensional tests should be generally applicable to large-scale, three-dimensional vehicles. In fact, with regard to the comparisons shown in figure 3 , tests performed using two-dimensional models were believed to be more representative of the large-scale flight vehicles than those performed with threedimensional models. The series of tests had two primary objectives:

1. Test the hypothesis regarding forebody roughness in a systematic manner to conclusively demonstrate existence of a viscous forebody dragbase drag optimum (the "drag bucket").

2. Establish a criterion for when forebody drag is suboptimal (that is, at what point does increasing forebody drag result in an overall drag reduction).

\section{Wind-Tunnel Model Description}

Figure 5 shows a three-view drawing of the wind-tunnel model. The machined-aluminum model consists of a $2.54-\mathrm{cm}$-diameter (1-in.) cylindrical leading edge with a flat-sided afterbody $11.43-\mathrm{cm}$

4 
(4.5-in.) long. Removable aluminum plates on the sides of the model allow various levels of surface roughness to be tested by interchanging the plates. The base-towetted area of the model is approximately 10.7 percent. Figure 6 shows the model mounted in the wind tunnel.

The forebody roughness of the model was increased by bonding micromachined brass overlays to the side plates. Figure 5 shows a sample of this roughness "screen" overlaid on the top view of the model. These "screens" consist of a series of transverse bars with the shim $(\tau)$, slot $(\Sigma)$, and "land" $(\lambda)$ dimensions determining the roughness of the surface. Figure 7 shows the geometric layout for these bar grid overlays. A single overlay geometry using lands and slots aligned parallel to the direction of flow was also tested. Table 1 shows the geometries tested, and the equivalent surface roughness $\left(\kappa_{s}\right)$ derived from empirical-fit formulae presented in Mills.

Table 1. Screen overlay roughness dimensions.

\begin{tabular}{ccccl}
\hline $\begin{array}{c}\text { Configuration } \\
\text { number }\end{array}$ & $\lambda, \mathrm{cm}$ & $\Sigma . \mathrm{cm}$ & $\tau, \mathrm{cm}$ & $\kappa_{\mathrm{s}}, \mathrm{cm}$ \\
\hline 1 & 0.0000 & 0.0000 & 0.0000 & $0.0000^{*}$ \\
2 & 0.0051 & 0.0051 & 0.0051 & $0.0163^{* *}$ \\
3 & 0.0254 & 0.0381 & 0.0254 & 0.1143 \\
4 & 0.0508 & 0.1016 & 0.0508 & 0.2896 \\
5 & 0.0508 & 0.2032 & 0.0508 & 0.4854 \\
6 & 0.1016 & 0.2540 & 0.1016 & 0.6911 \\
\hline
\end{tabular}

* Smooth model

** Parallel bars

\section{Wind-Tunnel Description}

The model was tested in a low-speed wind tunnel at the NASA Dryden Flight Research Center (Edwards, California). The ambient. open-cycle tunnel has a test section approximately 10 by $25 \mathrm{~cm}$ (4 by 10 in.). An alternating current $(A / C)$ motor uses a squirrel-cage fan located at the downstream end to pull air through the tunnel. When the model was mounted in the tunnel test section, the total blockage was 10 percent. This level of blockage is considered high for traditional wind-tunnel testing.

The primary effect of the blockage was to accelerate the flow around the model forebody. causing a rise in the dynamic pressure and a drop in the static pressure along the sides of the tunnel wall foutside of the tunnel wall boundary layer). The dynamic pressure rise (static pressure drop) was taken into account by calibrating local total and static pressure ratios-referenced to the dynamic and static pressure ahead of the model-as a function of the axial position in the tunnel. Figure 8 shows this calibration plot. At each pressure measurement location, the derived dynamic pressure was used to compute the local pressure coefficient.

$$
C_{p}(x)=\frac{\left[p(x)-p_{\text {sratio }}(x) p_{\infty}\right]}{\bar{q}_{\text {ratio }}(x) \bar{q}_{\infty}}
$$

With the model mounted in the wind tunnel, a maximum free-stream airspeed of approximately $28.0 \mathrm{~m} / \mathrm{sec}(92 \mathrm{ft} / \mathrm{sec})$ was achieved. Based on the model length, this free-stream velocity translates to a Reynolds number $\left(\operatorname{Re}_{L}\right)$ of approximately $2.25 \times 10^{5}$. Tests were also performed at airspeeds of approximately $14.6 \mathrm{~m} / \mathrm{sec}(48 \mathrm{ft} / \mathrm{sec})$. The corresponding $\mathrm{Re}_{L}$ for these lower-speed tests was approximately $1.25 \times 10^{5}$. The wind-tunnel turbulence intensity levels were sufficiently large that the model flow was turbulent beginning at the leading edge.

\section{Instrumentation}

All test measurements were performed using only pressure instrumentation. The methods used to interpret the measurements are presented in the "Analysis Methods" section. The tunnel itself was instrumented with series of static pressure taps along the side of the tunnel. Total (reference) pressure levels were sensed with a pitot probe placed five model lengths ahead of the model. A total of 16 pressure taps was distributed around the centerline of the model: 5 ports on the model forebody, 8 ports placed along the sides of the model, and 3 ports placed on the model base. These port locations allowed body pressure forces to be accurately integrated. Figure 5 shows the locations of the 16 model pressure ports. Several leading-edge ports can be seen on the model mounted in the tunnel (fig. 6).

The total model drag coefficient was measured by wake velocity profiles sensed using a traversing pitotstatic probe. Both local total and static pressures were sensed by this probe. The probe tip was placed $12.7 \mathrm{~cm}$ ( 5 in.) aft of the model base area. The wake probe tip diameter was approximately $0.025 \mathrm{~cm}$. Similar momentum-defect measurements for skin friction were performed at the model aft using a traversing boundary-layer pitot probe. For the boundary-layer profiles, only local total pressure was measured by the traversing probe. Local static pressure was assumed constant across the depth of the boundary layer. 
Free-stream static pressure at the model base was sensed by a side port on the tunnel wall. The boundary-layer probe tip diameter was approximately $0.02 \mathrm{~cm}$. Figure 6 shows the wake and boundary-layer probes mounted in the tunnel. The probe positions relative to the centerline of the model were measured using a digital micrometer. The estimated accuracy of the digital positioning sensor was approximately $0.0025 \mathrm{~cm}(0.001 \mathrm{in}$.).

All of the model, tunnel wall, and traversing probe pressure data were sensed with a highly accurate set of digital (RS-422) scanning pressure modules. These data were recorded by a laptop computer using the serial port to perform individual channel addressing. Full-scale span of these differential pressure modules was $\pm 2.490 \mathrm{kPa}\left( \pm 52.0 \mathrm{lbf} / \mathrm{ft}^{7}\right)$. The manufacturer's accuracy specifications for the differential pressure measurements is \pm 0.05 percent of full scale, or approximately $\pm 0.00125 \mathrm{kPa}\left( \pm 0.026 \mathrm{lbf} / \mathrm{ft}^{2}\right)$. The differential pressure transducers were referenced to the pitot probe placed approximately $64 \mathrm{~cm}$ (25 in.) ahead of the model. The reference pitot pressure was sensed with a highly accurate absolute pressure manometer. The estimated accuracy for the absolute reference pressure measurement is approximately $\pm 0.010 \mathrm{kPa}$ $\left( \pm 0.16 \mathrm{lbf} / \mathrm{ft}^{2}\right)$. The reference temperature was sensed externally to the tunnel using a type " $T$ " thermocouple with an estimated accuracy of approximately $\pm 0.5^{\circ} \mathrm{C}\left( \pm 0.9^{\circ} \mathrm{F}\right)$.

\section{$\underline{\text { Test Procedures }}$}

The low dynamic pressure levels-less than $0.4788 \mathrm{kPa}\left(10 \mathrm{lbf} / \mathrm{ft}^{2}\right)$-during this series of windtunnel tests required that data be taken with great consistency (1) minimize the effects of experimental procedure on the overall errors. For all test conditions and configurations. the transducers were zeroed prior to testing. and the model angle of attack was set to zero by comparison of the lefi and right surface model pressures. To set the zero angle-of-attack position. the model position was perturbed until the left and right surface pressure curves lay directly on top of each other.

\section{Transducer Zeroing}

Although the elecoronically scanned pressure transducers have a built-in feature that allows the transducers to be zeroed on-line. experimentation determined that a superior level of bias correction was achieved when the transducers were manually zeroed before each data run. Transducer biases were evaluated by taking readings with the tunnel in the "off" position (zero airspeed). In this zeroing process, each pressure port was addressed a total of 100 times and these data samples were averaged to minimize the effects of random sensor errors. The resulting zero readings were written to an archival file for later use by postprocessing analysis algorithms.

\section{Surface Pressure Scans}

The pressure scans read data from the 16 model pressure ports as well as the total and static pressure levels in the tunnel. For each configuration tested-that is, each different grid pattern or airspeed-the pressure scans were repeated ten times. For each of the ten measurement sequences, the zeroing procedure was performed and the tunnel was activated and allowed to stabilize. Typically, 100 individual data samples were averaged for each data run to minimize the effects of random measurement errors and tunnel turbulence. After ten pressure scans were taken for each configuration, the data were converted to pressure coefficients by postprocessing algorithms and the pressure coefficients data were averaged. The standard deviation of the ten measurement sequences data was used as a representation of the end-to-end accuracy of the measurement system. Typically the end-to-end pressure coefficient error varied between \pm 0.003 and \pm 0.005 .

\section{Wake and Boundary-Layer Surveys}

For the wake surveys, each data point consists of a pitot and a static-pressure measurement taken at a single lateral offset $(y)$ from the model centerline. For the boundary-layer surveys, each data point consists of a pitot measurement taken at a lateral offset and a wall static pressure measurement. For each data point, 100 data samples were averaged to minimize the effects of random measurement errors and tunnel turbulence. To completely define the wake profile, approximately 200 '-position data points were required. For early tests in the tunnel, the entire wake profile was measured. These data were so symmetrically distributed that as a timesaving measure, later tests only surveyed one-half of the wake profile.

Because of the large number of data samples (approximately 20,000) required to define the wake for each measurement configuration, completing each of the wake surveys ten times as was done with the pressure survey data was considered impractical. Instead, each wake survey was performed twice and the resulting data were interleaved to form a single local velocity distribution profile. At the beginning of each of the two wake surveys, the probe sensor zero readings were taken and written to an archival file for use by the

6 
postprocessing routines. When computed, transducer biases were assumed constant for the duration of each wake survey.

\section{Analysis Methods}

This section derives the analysis methods used in this series of wind-tunnel tests. A baseline set of twodimensional, incompressible, computational fluid dynamics (CFD) calculations will be presented first. Next, the viscous calculations used to convert the measured wind-tunnel pressures data into the various components of the drag coefficient will be presented. For each analysis method presented in this section, an error analysis is also presented in the appendix.

\section{Computational Fluid Dynamics Analysis}

The CFD calculations were performed to give pretest drag predictions to verify that the smooth model configuration lay on the suboptimal portion of Hoerner's base drag curve.

Only the CFD estimates of forebody pressure and base drag coefficients were used for the pretest drag predictions. Not enough computational cells were embedded within the boundary layer to allow the skin-friction coefficient to be accurately computed. using the CFD data. The integrated skin drag coefficient was predicted using the two-dimensional Hoerner drag model.

The CFD flow calculations were performed using a commercially available code. ${ }^{8}$ The core solver for this code features a finite-volume, cell-centered discretization, and uses a time-accurate, "PISO" (pressure-implicit with splitting of operators) solution algorithm to solve the integral form of the Navier-Stokes equations. Although the code has compressibility and transient solution capabilities, only the incompressible steady-state solution was used in this analysis. The analysis was set up to force turbulence at the leading edge of the model. For this analysis, a simple $\kappa-\varepsilon$ (energy-dissipation) turbulence model was used.

Figure 9 shows the predicted CFD model flow field. The CFD solutions clearly show a periodic vortex structure trailing the model. When the pressure forces are summed along the surface of the model and projected perpendicular to the longitudinal axis, the integrated forebody pressure coefficient is approximately -0.018 and the integrated base drag coefficient is approximately 0.035 . Based on data shown in figure 2 , the smooth model should lie on the suboptimal side of Hoerner's drag curve. Thus, by adding roughness to the forebody, the overall drag coefficient should be reduced.

\section{Wake Profile Analysis}

This analysis method fits the wind-tunnel wake data with a symmetric "cosine law" velocity distribution profile of the form

$$
\frac{u(y)}{U_{e}}=\frac{1}{2}\left[\frac{u_{\min }}{U_{e}}\left[1+\cos \left(\pi \frac{y}{\delta}\right)\right]+\left[1-\cos \left(\pi \frac{y}{\delta}\right)\right]\right]
$$

In equation (2), $u_{\min }$ is the minimum velocity in the wake, $y$ is the lateral distance outwards from the center of the wake, $U_{e}$ is the velocity at the edge of the wake, $u(y)$ is the local velocity within the wake, and $\delta$ is the wake half-width. A least-squares method was used to curve-fit the measured velocity distribution data to the profile assumed in equation (2). In this method, equation (2) is rewritten as a linear system of the form

$$
Z^{(\text {meas })}=A X^{(k)}+C
$$

where

$$
Z^{(\text {meas })}=\left[\begin{array}{c}
\frac{u\left(y_{1}\right)}{U_{e}} \\
\cdot \\
\cdot \\
\frac{u\left(y_{n}\right)}{U_{e}}
\end{array}\right] X^{(k)}=\left[\begin{array}{c}
\cos \left(\pi y_{1} / \hat{\delta}^{(k)}\right) \\
\cdot \\
\cdot \\
\cos \left(\pi y_{n} / \hat{\delta}^{(k)}\right)
\end{array}\right]
$$

and

$$
A=\frac{1}{2}\left[\frac{u_{\min }}{U_{e}}-1\right] \quad C=\frac{1}{2}\left[\frac{u_{\min }}{U_{e}}+1\right]
$$

A simple least-squirms method is used to solve for estimates of the slope and intercept parameters, $A$ and $C$ : 


$$
{\hat{u_{\min }}}^{(k)}=\hat{A}^{(k)}+\hat{C}^{(k)}
$$

Using a first-order perturbation, equation (4) can be "updated" using nonlinear regression to get a refined value for $\delta$ :

$$
Z^{(\text {meas })}-\hat{Z}^{(k)}=\hat{A}^{(k)} \nabla_{\delta} X^{(k)}\left[\hat{\delta}^{(k+1)}-\hat{\delta}^{(k)}\right]
$$

where

$$
\nabla_{\delta} X^{(k)}=\left[\begin{array}{c}
\left(\pi \frac{y_{1}}{\left[\delta^{(k)}\right]^{2}}\right) \sin \left(\pi \frac{y_{1}}{\delta^{(k)}}\right) \\
\cdot \\
\cdot \\
\left.\pi \frac{y_{n}}{\left[\delta^{(k)}\right]^{2}}\right) \sin \left(\pi \frac{y_{n}}{\delta^{(k)}}\right)
\end{array}\right]
$$

After extensive algebra, the least-squares solution to equations (5) and (6) can be written as

$$
\begin{aligned}
\hat{\delta}^{(k+1)}=\hat{\delta}^{(k)} & \sum_{i=1}^{n}\left\{\left[\frac{\pi y_{i}}{\left[\hat{\delta}^{(k)}\right]^{2}} \sin \left[\frac{\pi y_{i}}{\delta}\right]\right]\left[z_{i}-\hat{z}_{i}^{(k)}\right]\right\} \\
+ & \frac{\hat{A}^{(k)} \sum_{i=1}^{n}\left[\frac{\pi y_{i}}{\left[\hat{\delta}^{(k)}\right]^{2}} \sin \left[\frac{\pi y_{i}}{\left.\hat{\delta}^{(k)}\right]}\right]^{2}\right.}{}
\end{aligned}
$$

Assuming that a starting value for the wake half-width, $\delta^{(0)}$, is known beforehand (from visual inspection of the wake data), equations (4)-(7) are solved iteratively until convergence. Convergence typically takes less than ten iterations.

Figure 10 shows an example wake curve fit compared with the wind-tunnel data. These data were obtained from the smooth model configuration tested at $\mathrm{Re}_{l}=2.25 \times 10^{5}$. The turbulent wake extends beyond the lateral boundaries of the wind-tunnel model by approximately $3 \mathrm{~cm}$. The wake structure is symmetric and the cosine velocity distribution law gives a reasonable curve fit. Note that the center of the wake appears to contain a significant amount of turbulence that significantly decreases near the edge of the wake.

When the velocity profile has been curve-fit, equation (1) is substituted into the equations for the wake displacement and momentum thickness and analytically evaluated to give

$$
\delta^{*}{ }_{w^{\prime}}=\int_{-\delta}^{\delta}\left[1-\frac{u(y)}{U_{e}}\right] d y=\delta\left[1-\frac{u_{\min }}{U_{e}}\right]
$$

and

$$
\begin{aligned}
& \theta_{w}=\int_{-\delta}^{\delta} \frac{u(y)}{U_{e}}\left[1-\frac{u(y)}{U_{e}}\right] \\
& d y=\frac{\delta}{4}\left[1+2 \frac{u_{\min }}{U_{e}}-3\left[\frac{u_{\min }}{U_{e}}\right]^{2}\right]
\end{aligned}
$$

In equations (8) and (9), $u(y)$ is the local velocity in the wake at lateral offset location $y$, and $U_{e}$ is the local velocity at the edge of the wake. The free-stream momentum thickness is calculated from the local momentum thickness using the well-known SquireYoung formula: ${ }^{10}$

$$
\theta_{\infty}=\theta_{n}\left[\frac{U_{e}}{U_{\infty}}\right]^{\frac{1}{2}|H+5|}
$$

Equation (10) corrects for the effects of the wind tunnel blockage described earlier in this paper. In equation (10), $H$ is the wake shape parameter defined by

$$
H=\frac{\delta^{*}{ }_{w}}{\theta_{w}}
$$

The free-stream drag coefficient is computed from the normalized section drag

$$
C_{D_{0}}=\frac{D^{\prime}}{\frac{1}{2} \rho U_{\infty}^{2} h_{b a s e}}=2 \frac{\theta_{\infty}}{h_{\text {base }}}
$$

An approximate accounting of overall error in the wake drag coefficient can be performed using a linear perturbation analysis. The appendix shows this linearized error analysis. 


\section{Boundary-Layer Profile Analysis}

The forebody skin friction coefficient is evaluated using the boundary-layer velocity profiles in a similar manner as the wake analysis presented earlier. In this case, however, Coles" "law of the wake,"

$$
u^{+}=\frac{1}{\kappa}\left[\ln \left[y^{+}\right]+2 \Pi \sin ^{2}\left[\frac{\pi y}{2} \frac{y}{\delta}\right]\right]+B
$$

is curve-fit to the local velocity profile data. The law of the wake is a very general experimental correlation for turbulent boundary layers, and relates the nondimensional velocity

$$
u^{+}=\frac{u(y)}{U_{e}\left[\sqrt{\frac{1}{2} c_{f}}\right]}
$$

to the nondimensionalized boundary-layer coordinate

$$
y^{+}=\frac{y}{x} \operatorname{Re}_{x}\left[\sqrt{\frac{1}{2} c_{f}}\right]
$$

In equations (13)-(15), $\delta$ is local boundary-layer thickness, $K$ is the law-of-the-wake slope parameter, $B$ is the law-of-the-wake bias parameter, $\Pi$ is the wake pressure gradient parameter, and $c_{f_{x}}$ is the local skin-friction coefficient. The accepted "best value" for $\kappa$ currently is $0.41 .{ }^{10}$ The bias parameter, $B$, varies with the level of surface roughness and for a smooth plate has a numerical value of approximately $5.0 . \mathrm{Re}_{x}$ is the Reynolds number based on the local axial coordinate, $x$.

The roughness dependent bias term can be eliminated from equation (13) by expressing the law of the wake in terms of the local "velocity defect":

$$
\left[1-\frac{u(y)}{U_{c^{\prime}}}\right]=\sqrt{\frac{1}{2} c_{f}} \frac{1}{\kappa}\left[2 \Pi \cos ^{2}\left[\frac{\pi y}{2} \frac{y}{\delta}\right]-\ln \left[\frac{y}{\delta}\right]\right]
$$

The wake parameter. $\Pi$, is proportional to the local longitudinal pressure gradient. Das ${ }^{10.12}$ has established an empirical correlation that relates the wake parameter to the more familiar "Clauser parameter, ${ }^{, 13} \beta$, where

$$
0.42 \Pi^{2}+0.76 \Pi-0.4=\beta=\frac{2}{c_{f_{x}} \frac{1}{2} \rho U_{e}{ }^{2}} \frac{\delta^{*}}{d x}
$$

In equation (17), $\delta^{*}$ is the local displacement thickness, $c_{f}$ is the local skin-friction coefficient, and $d P_{e} / d x$ is the longitudinal pressure gradient at the edge of the boundary layer. Based on the correlation of equation (17), the numerical value of $\Pi$ corresponding to a zero pressure gradient flow is approximately 0.426 . Earlier authors have placed this zero gradient value at approximately $0.5^{10}$ and $0.55 .^{7}$ For this analysis, the more modern value recommended by Das is used. A value for $\Pi$ greater than the zero gradient value $(0.426)$ corresponds to an adverse pressure gradient. A value for $\Pi$ less than the zero gradient value $(0.426)$ corresponds to a favorable pressure gradient. ${ }^{10}$

Following the procedure used earlier with the wake integral analysis, equation (16) is rewritten as a linear system of the form

$$
\left[\begin{array}{c}
z_{1} \\
\cdot \\
\cdot \\
z_{n}
\end{array}\right]=\Gamma\left[\begin{array}{c}
x_{1} \\
\cdot \\
\cdot \\
x_{n}
\end{array}\right]
$$

where

$$
\begin{aligned}
z_{i} & =\left[1-\frac{u\left(y_{i}\right)}{U_{e}}\right] \Gamma=\sqrt{\frac{c_{f_{1}}^{(k)}}{2}} \\
x_{i}{ }^{(k)} & =\frac{1}{\kappa}\left[2 \Pi^{(k)} \cos ^{2}\left[\frac{\pi}{2} \frac{y_{i}}{\hat{\delta}^{(k)}}\right]-\ln \left[\frac{y_{i}}{\hat{\delta}^{(k)}}\right]\right]
\end{aligned}
$$

In equations (18)-(19), the subscript $i$ is the measurement, and the superscript $(k)$ is the iteration index. After some extensive algebra, the least-squares solution to equation (19) can be written as

$$
\begin{aligned}
r_{f_{x}} & =2\left[\sum_{i=0}^{n}\left(x_{i=} z_{i}\right) / \sum_{i=0}^{n}\left(x_{i}^{2}\right)\right]^{2} \\
& =2\left[\frac{\sum_{i=0}^{n} \frac{1}{k}\left[2 \Pi \cos ^{2}\left[\frac{\pi}{2} \frac{y_{i}}{\hat{\delta}^{(k)}}\right]-\ln \left[\frac{y_{i}}{\left.\hat{\delta}^{(k)}\right]}\right]\left[1-\frac{u\left(\frac{y_{i}}{\delta}\right)}{U_{i^{\prime}}}\right]\right]^{2}}{\sum_{i=0}^{n}\left\{\frac{1}{\kappa}\left[2 \Pi \cos ^{2}\left[\frac{\pi}{2} \frac{y_{i}}{\hat{\delta}^{(k)}}\right]-\ln \left[\frac{y_{i}}{\hat{\delta}^{(k)}}\right]\right]\right\}^{2}}\right]^{(20)}
\end{aligned}
$$

Using a first-order perturbation with respect to $\delta$, equation (20) can be updated using nonlinear regression to get a refined value for $\delta$ : 


$$
Z^{(\text {meas })}-\hat{Z}^{(k)}=\Gamma^{(k)} \nabla_{\delta} \hat{X}^{(k)}\left[\hat{\delta}^{(k+1)}-\hat{\delta}^{(k)}\right]
$$

where the $i^{\text {th }}$ component of the $Z$ vector is

$$
\hat{\hat{z}}_{i}^{(k)}=\sqrt{\frac{c_{f_{x}}^{(k)}}{2} \frac{1}{\kappa}}\left[2 \Pi \cos ^{2}\left[\frac{\pi}{2} \frac{y_{i}}{\hat{\delta}^{(k)}}\right]-\ln \left[\frac{y_{i}}{\hat{\delta}^{(k)}}\right]\right]
$$

The resulting updated equation for $\delta$ is

$$
\begin{aligned}
& \hat{\delta}^{(k+1)} \\
& =\left(\dot{\delta}^{(k)}+\left\{\left[\nabla_{\delta} \hat{x}^{(k)}\right]^{\mathrm{T}}\left[\nabla_{\delta} \hat{x}^{(k)}\right]\right\}\right) \\
& \times\left\{\left[\nabla_{\delta} \dot{x}^{(k)}\right]^{\mathrm{T}}\left[z^{(\text {meas })}-\hat{Z}^{(k)}\right]\right\} \\
& =\dot{\delta}^{(k)} \\
& +\frac{\sum_{i=1}^{n}\left\{\frac{1}{\hat{\delta}^{(k)}}\left[1+\pi \Pi \frac{y_{i}}{\hat{\delta}^{(k)}} \sin \left[\pi \frac{y_{i}}{\hat{\delta}^{(k)}}\right]\right]\left[\dot{z}_{i}^{(\text {meas })}-\dot{\xi}_{i}^{(k)}\right]\right\}}{\sum_{i=1}^{n}\left[\frac{1}{\hat{\delta}^{(k)}}\left[1+\pi n \frac{y_{k}}{\hat{\delta}^{(k)}} \sin \left[\pi \frac{y_{i}}{\hat{\delta}^{(k)}}\right]\right]\right]^{2}}
\end{aligned}
$$

When the variational algorithm of equations (21)-(23) is modified to allow direct estimation of $\Pi$ along with $\delta$ and $c_{f}$, the equations rapidly diverge. To circumvent this numerical problem. $\Pi$ was selected for this analysis to give the best overall fit consistency. This procedure typically consisted of selecting a starting value for $I I$ and then computing $c_{f}$, and $\delta$ by iteratively solving equations (21)-(23) until convergence. At this point, the value for $\Pi$ was varied by a small amount and the iterative algorithm was repeated. If the total fit error improved. then $\Pi$ was again varied in the same direction; if not, then the value was varied in the opposite direction. Using this ad hoc procedure. a minimum fit error is typically reached after less than ten trials.

Figure 11 shows an example boundary-layer curve fit compared with the wind-tunnel data. The normalized velocity distribution is plotted against the normalized position within the boundary layer. These data were obtained from the smooth model configuration tested at $\operatorname{Re}_{L}=2.25 \times 10^{5}$. Three fit curves are plotted here: a law-of-the-wake curve fit with $\Pi=0.426$ (zero pressure gradient); a law-of-the-wake curve fit with the wake parameter adjusted to give the minimum fit error,
$\Pi=1.032$; and a $1 / 7^{\text {th }}$-power-curve exponential curve fit. Analysis of equation (17) presented in White ${ }^{10}$ shows that $\Pi=1.032$ corresponds to a weak adverse pressure gradient. The model data presented in the "Results and Discussion" section support this conclusion. Clearly, the curve fit using $\Pi=1.032$ gives overall fit consistency.

The estimated values for $\delta, c_{f_{x}}$, and $\Pi$ are used to calculate the local momentum and displacement thickness by integrating the law of the wake across the depth of the boundary layer. As derived in White, ${ }^{10}$ the resulting expressions for the displacement and momentum thickness are

$$
\frac{\delta^{*}}{\delta}=\sqrt{\frac{c_{f_{x}}}{2}} \frac{1+\Pi}{\kappa}
$$

and

$$
\frac{\theta}{\delta}=\frac{1}{\kappa} \sqrt{\frac{f f_{x}}{2}}\left[(1+\Pi)-\frac{1}{\kappa} \sqrt{\frac{f f_{x}}{2}}\left(2+3.2 \Pi+1.5 \Pi^{2}\right)\right]
$$

For simplicity, the effect of the local laminar sublayer is ignored in equations (24) and (25). For the Reynolds numbers tested, earlier analysis estimates that ignoring the laminar sublayer introduces integral errors of less than 0.2 percent. ${ }^{12}$ When the local momentum and displacement thickness have been evaluated, then the integrated viscous forebody drag coefficient can be evaluated using the "Clauser" form of the von Karman momentum equation, ${ }^{10}$

$$
\frac{d \theta}{d x}-(2+H) \frac{\beta^{c}}{H} \frac{{ }_{f_{x}}}{2}=\frac{{ }^{c} f_{x}}{2}
$$

In equation (26), $H=\delta^{*} / \theta$ is the boundary-layer shape parameter. The Clauser parameter, $\beta$, is related to the local pressure gradient, the displacement thickness, and the local skin-friction coefficient as

$$
\beta \frac{f_{r}}{2}=\frac{\delta^{*}}{\frac{1}{2} \rho U_{e}^{2}} \frac{d P_{e}}{d x}
$$

Solving equations (26) and (27) for the local skinfriction coefficient gives

$$
c_{f_{,}}=2 \frac{d \theta}{d x} \frac{H}{|H+(2+H) \beta|}
$$


As demonstrated by Clauser, ${ }^{13}$ for small-to-moderate pressure gradients, the terms on the right side of equation (28), $\frac{H}{[H+(2+H) \beta]}$, are approximately constant. Integrating equation (28) along the forebody length, $L$, gives

$$
\begin{aligned}
C_{F} & =\frac{1}{L} \int_{0}^{L} 2 \frac{d \theta}{d x} \frac{H}{[H+(2+H) \hat{\beta}]} d x \\
& \approx 2 \frac{\theta}{L} \frac{H}{(H+(2+H) \hat{\beta}]}
\end{aligned}
$$

As with the earlier wake analysis, an approximate accounting of overall error in the wake drag coefficient can be performed using a linear perturbation analysis. The appendix show's this linearized error analysis.

\section{Forebody Pressure Analysis}

The forebody pressure coefficient was evaluated by curve-fitting the pressure distributions as a function of local incidence angle. 0 . For the forebody data, seven forebody pressures-ports 1, 2, 3, 4, 14, 15, and 16 (fig. 5)-are curve-tit with a third-order polynomial The forebody pressure drag coefficient is analytically given by the surface integral

$$
\begin{aligned}
C_{D_{\text {furtetath }}} & =\int_{0}^{\pi / 2} C_{r}(\theta) \cos (\theta) d \theta \\
& =\int_{0}^{\pi / 2}\left[\sum_{1=0}^{3} a_{1} \theta^{\prime} \cos [\theta]\right] d \theta \\
& =a_{0}+0.5708 a_{1}+0.4674 a_{2}+0.4510 a_{3}
\end{aligned}
$$

Figure 12 shous a plot of a sample forebody curve fit These smooth model data were measured with the wind tunnel operating at $\mathrm{Re}_{l}=2.25 \times 10^{5}$. The forebody pressure coefficient datil is plotted as a function of the local incidence angle. The upper and lower surface pressure data lie nearly superimposed on each other, so not surprisingly. the third-order curve-fit closely matches the pressure coefficient data.

\section{Base Pressure Analysis}

The base pressure coefficient was evaluated by curve-fitting the base pressure distributions as a function of the lateral offset coordinate, $y$. For the base pressure data, five base area pressure ports-ports 7, 8, 9, 10, and 11 (fig. 5)-were curve-fit with a fourth-order polynomial. The pressure ports on the sides of the model (ports 7 and 11) were included in the curve fit to account for the taper of the base pressure near the outer edges of the model. In this curve-fitting scheme, ports 7 and 11 were weighted one-half as much as the three base area ports (ports 8,9 , and 10). This weighting scheme was selected to give a base drag taper correction factor of approximately 0.925 . This correction factor is suggested by Saltzman, et al. ${ }^{5}$ for full-scale flight vehicles.

The base pressure drag coefficient is given analytically by the evaluating the surface integral

$$
\begin{aligned}
C_{D_{\text {buse }}} & =\int_{-0.5^{\prime \prime}}^{0.5^{\prime \prime}} C_{p}[y] d y=\int_{-0.5^{\prime \prime}}^{0.5^{\prime \prime}}\left[\sum_{0}^{4} b_{i} y^{i}\right] d y \\
& =b_{0}+0.0833 b_{2}+0.0125 b_{4}
\end{aligned}
$$

Figure 13 shows a sample base pressure distribution curve fit. These data were measured on the smooth model with the wind tunnel operating at an approximate Reynolds number of $2.25 \times 10^{5}$, based on model length.

\section{$\underline{\text { Results and Discussion }}$}

The wind-tunnel data clearly support the earlier CFD predictions that the smooth model will lie on the suboptimal side of Hoerner's curve. The suboptimal hypothesis is most clearly demonstrated by examining the base area pressure distributions. Figure 14 shows these results. The base pressure coefficients are plotted here as a function of $y$ for various surface grid patterns. Figure 14(a) shows the pressure distributions for $\operatorname{Re}_{L}=2.25 \times 10^{5}$, and figure 14(b) shows the pressure distributions for $\operatorname{Re}_{L}=1.25 \times 10^{5}$. Interestingly, the surface pattern with fine-mesh parallel slots and lands causes the base drag to dramatically rise (and have lower base pressure coefficients) when compared with the smooth surface model. Conversely, the surface pattern with transverse slots and lands causes the base drag to gradually lower (and have higher base pressure coefficients) when compared to the smooth surface model.

A similar behavior was observed by Krishnan. et al., ${ }^{14}$ when the authors added riblet ${ }^{15}$ structures to the forebody of an axisymmetric wind-tunnel model with a blunt base. The authors' intents were that the riblets would lower base drag; however, the results were opposite of expectations. When Krishnan's results and the data presented in figure 14 are interpreted considering Hoerner's curve (fig. 3), the rising base drag is completely reasonable. The grid pattern with parallel slots and lands has the effect of acting like riblets on the model forebody. The riblet structures have the effect of lowering the forebody drag coefficient. Because the 
forebody skin drag coefficient is lowered, the base drag is expected to correspondingly increase. Clearly, riblets should not be used in conjunction with "suboptimal" configurations that have highly separated base regions; their effect will cause the base drag to rise.

Figure 15 shows results from the wind-tunnel tests that further illustrate this concept. The measured base drag coefficient is plotted with the viscous forebody drag coefficient calculated from the boundary-layer survey data. These data are compared to the curve fit of Hoerner's two-dimensional data from figure 1 . The open symbols represent data for $\mathrm{Re}_{L}=2.25 \times 10^{5}$ and the closed symbols represent data for $\mathrm{Re}_{L}=1.25 \times 10^{5}$. The error bars show the expected " $1-\sigma$ " standard deviations based on the error analyses presented earlier. The agreement with the curve fit of Hoerner's data is reasonably good.

Figure 16 shows the model total drag coefficient data (as calculated from the wake survey data) plotted with the viscous forebody drag coefficient. The error bars show the expected " $1-\sigma$ " standard deviations based on the error analyses presented earlier. Figure 16 also shows the predicted drag curve defined using Hoerner's two-dimensional curve from figure 1 , the viscous forebody drag measurement, and the model forebody drag coefficient predicted $(-0.018)$ by the CFD solutions. Note that, with the exception of the data for the parallel grid (riblets) overlay, the agreement with the predicted drag curve is very good.

The disagreement for the parallel grid test points is caused by a sharp rise in the forebody pressure coefficients. Figure 17 shows these data. The forebody pressure distributions for all of the grids are plotted here as a function of the local incidence angle. Figure 17(a) shows the higher Reynolds number data $\left(2.25 \times 10^{5}\right)$, and figure 17 (b) shows lower Reynolds number data $\left(1.25 \times 10^{5}\right)$. The transverse grid patterns do not significantly alter the forebody pressure distribution; however, the forebody pressure data are considerably higher for the parallel grid pattern. The parallel grid data are clearly an anomaly. The reasons for this pressure anomaly are not clear at this point, but the parallel grid possibly caused relaminarization of the flow and induced a localized separation. This anomaly requires further investigation.

Most importantly, the data shown in figure 16 demonstrate the existence of a drag minimum with regard to the viscous forebody drag coefficient. The elusive "drag bucket" is clearly defined and the primary hypothesis of this paper is conclusively proven. The drag reduction from the smooth model configuration to the optimum point is approximately 15 percent. Also, comparison of figure 15 with figure 16 shows that the base drag coefficient corresponding to the total drag coefficient minimum lies somewhere between 0.225 and 0.275 . This value is a bit lower than the $0.25-0.30$ range predicted by analysis of Hoerner's original data (figs. 2 and 3).

\section{Summary and Concluding Remarks}

Current designs of transatmospheric crew return and reusable launch vehicles have extremely large base-towetted area ratios when compared to conventional vehicle designs. These truncated base areas are highly separated, resulting in large, negative, base pressure coefficients. Because of the large base-to-wetted-area ratio, base drag makes up the majority of overall vehicle drag. Any reduction in base drag directly improves vehicle performance, resulting in an enhanced lift-todrag ratio, extended range, and a less-severe approach glide slope.

Early work performed on blunt-based bodies offers a potential solution. For blunt-based bodies, a direct correlation exists between base and "viscous" forebody drag. As the forebody drag coefficient increases, the base drag of the projectile generally tends to decrease. This base drag reduction results from boundary-layer effects at the vehicle base. Conceptually, if the added increment in forebody skin drag is optimized with respect to the base drag reduction, then reducing the overall drag of the configuration may be possible.

In order to test the above concept, a series of small-scale wind-tunnel tests was conducted. In these tests, a two-dimensional cylinder with a blunt afterbody was tested. The series of tests had two primary objectives: to test the forebody roughness hypothesis in a systematic manner to conclusively demonstrate existence of a "drag bucket"; and to establish a criterion for when forebody drag is suboptimal (that is. when will increasing forebody drag result in an overall drag reduction).

This paper presents the wind-tunnel test results. Both primary objectives were satisfied. These wind-tunnel results conclusively demonstrate existence of a forebody drag optimum. Also, the wind-tunnel data demonstrate that the base drag coefficient corresponding to the total drag minimum lies somewhere between 0.225 and 0.275 . This optimality point is slightly lower 
than the $0.25-0.30$ range predicted by analysis of Hoerner's original data. The use of parallel grid lines that emulate the effects of riblet structures on bodies with highly separated base regions will likely cause the total drag of the configuration to rise. Most importantly, the data show a peak drag reduction was approximately 15 percent. When this 15 -percent drag reduction is scaled to the size of the $X-33$ vehicle, the drag savings approaches approximately $45,000 \mathrm{~N}(10,000 \mathrm{lbf})$.

Clearly, this experiment should be repeated for different ranges of Reynolds number and aspect ratios to determine if the lower optimality point indicated by the data is real. The methods should also be demonstrated as being effective in the presence of induced drag. Practical implementation methods that allow for on-line adaptive modification of the forebody drag coefficient to seek the optimal point should be explored and developed. The limits of practical applicability for this technology are unknown at this point. This drag reduction technology is still in its infancy; however, a wide spectra of potential users exist, including the aerospace, automotive, ground transport, and shipping industries. Use of this drag reduction technique offers the potential for decreased operating costs resulting from decreased overall fuel consumption.

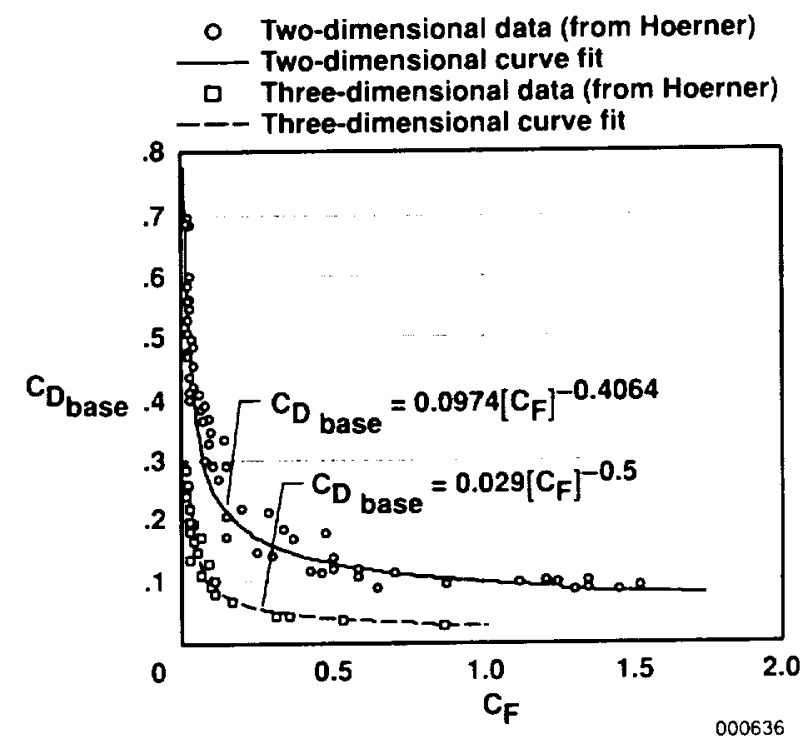

Figure 1. The effect of the viscous forebody drag on the base drag of a blunt-based projectile. 


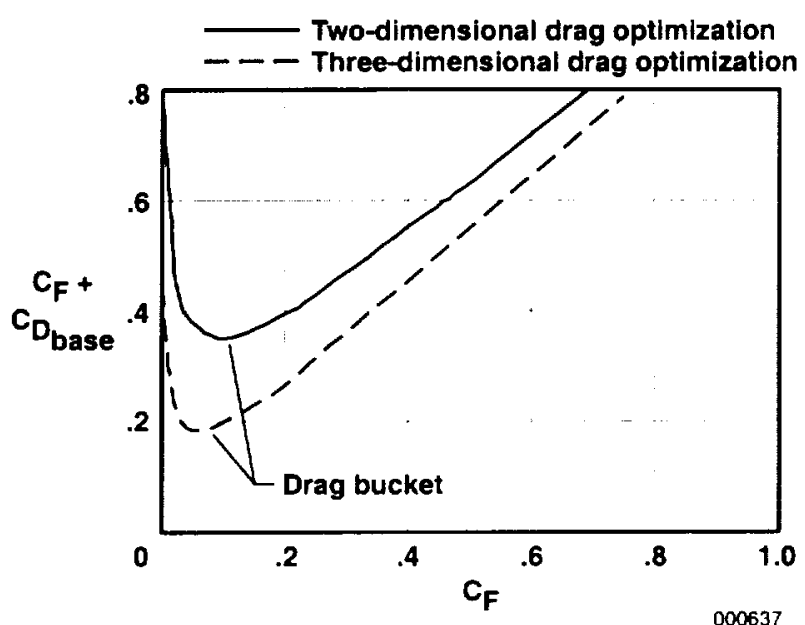

Figure 2. Schematic depiction of the predicted "drag bucket."

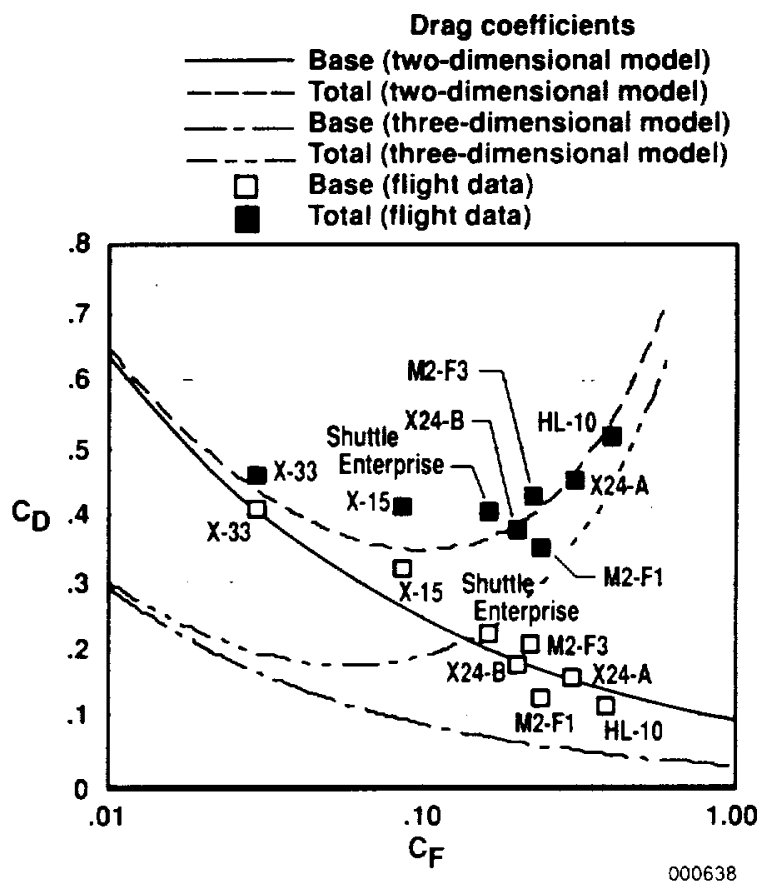

Figure 3. Comparison of flight data to two- and three-dimensional drag models. 


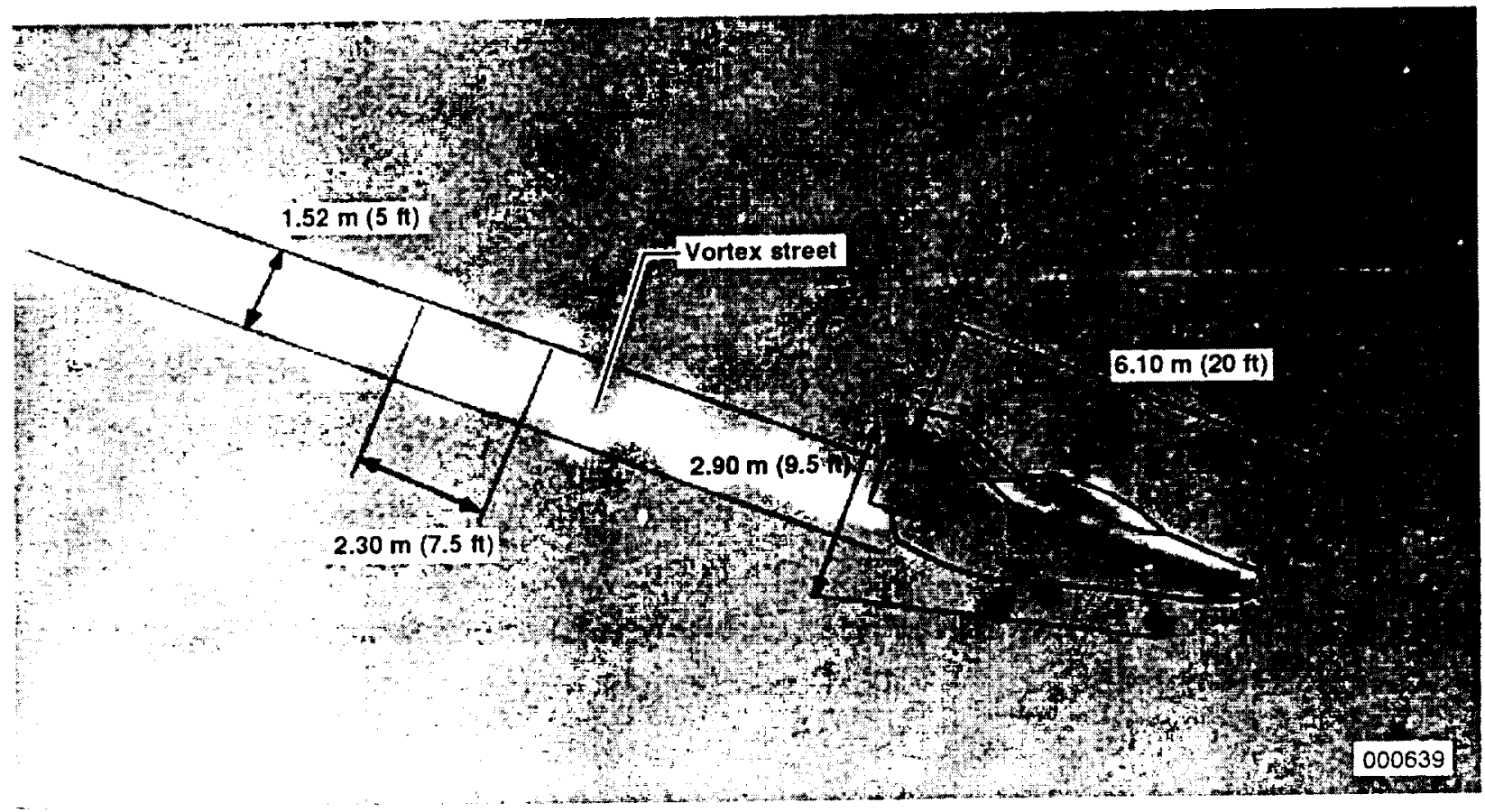

Figure 4. Von Karman "vortex street" formation trailing the M2-F1 vehicle. 


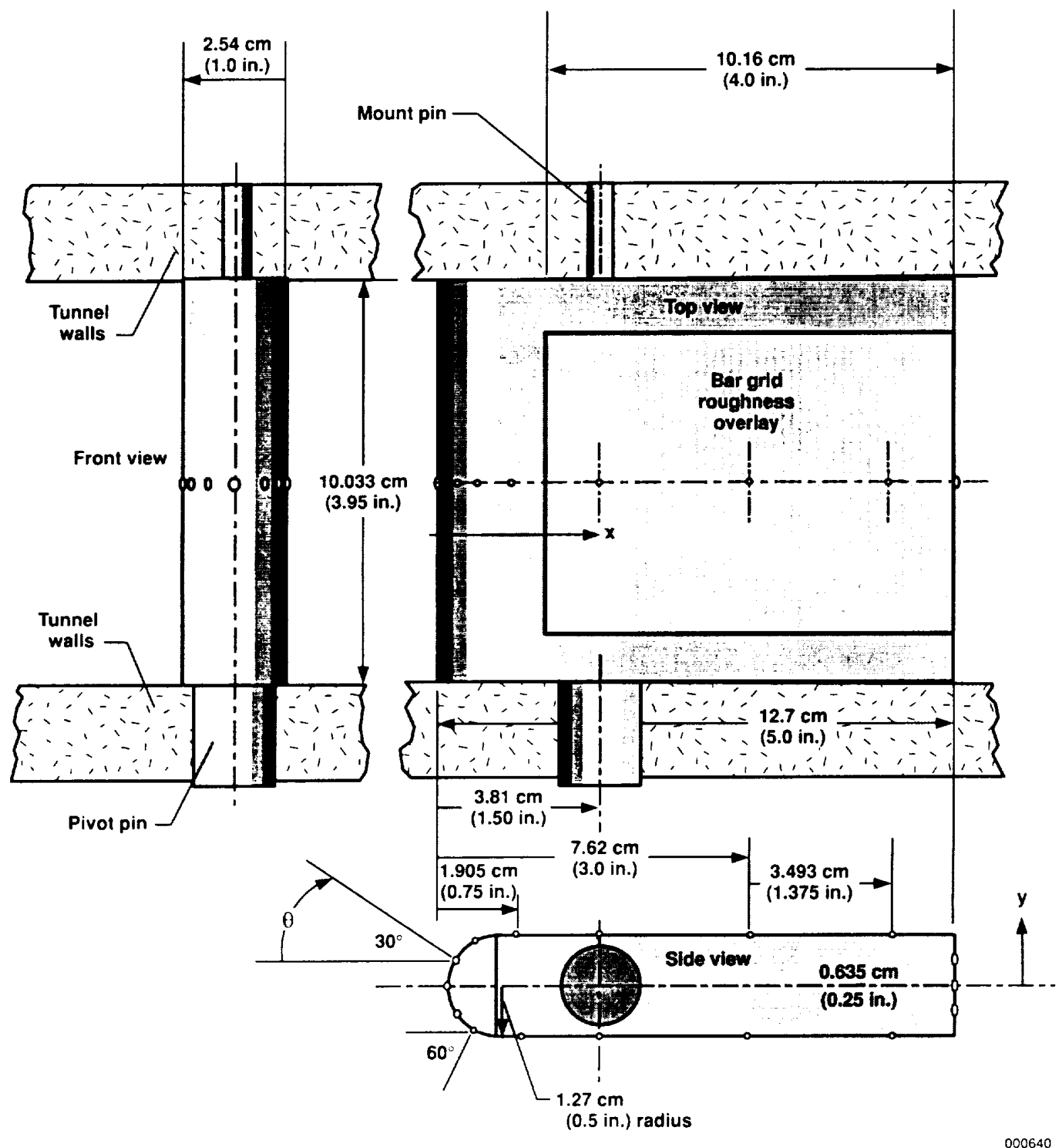

(a) Three-view drawing

Figure 5. Schematic of wind-tunnel model. 


\section{Model top view, looking down}

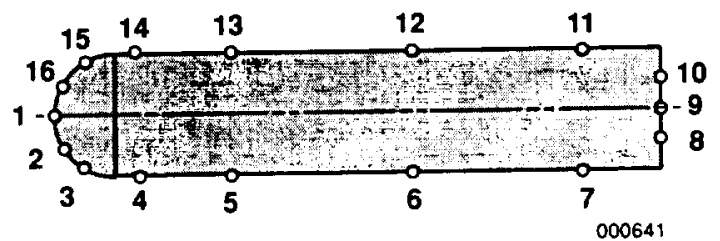

(b) Pressure port numbering scheme.

Figure 5. Schematic of wind-tunnel model. Concluded.

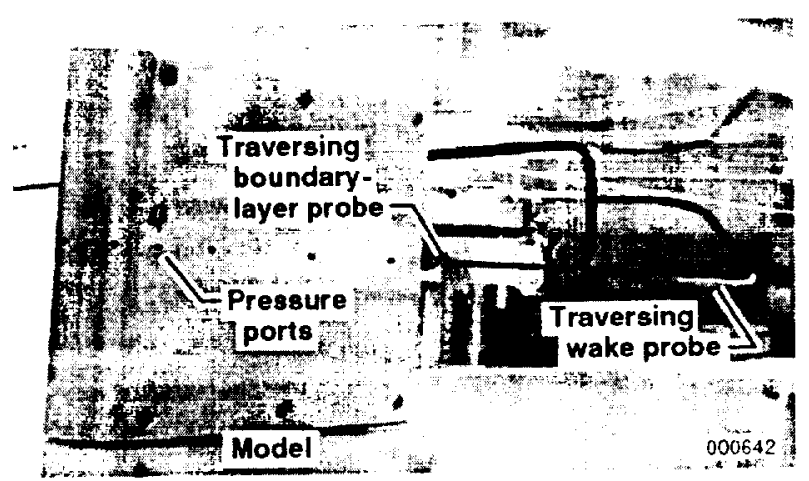

Figure 6. Base drag model mounted in wind tunnel. 


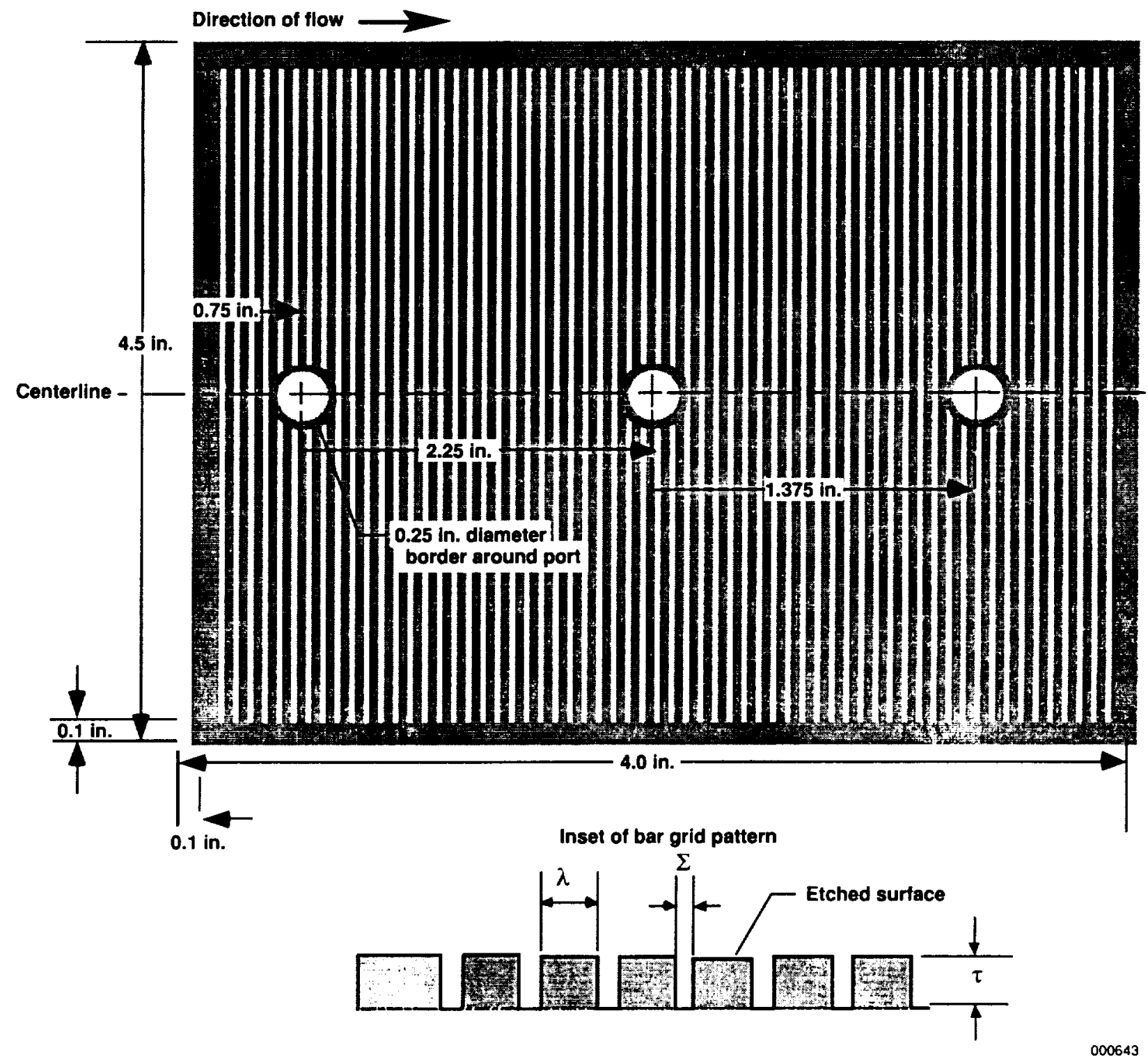

Figure 7. Bar grid surface overlay screen pattern. 


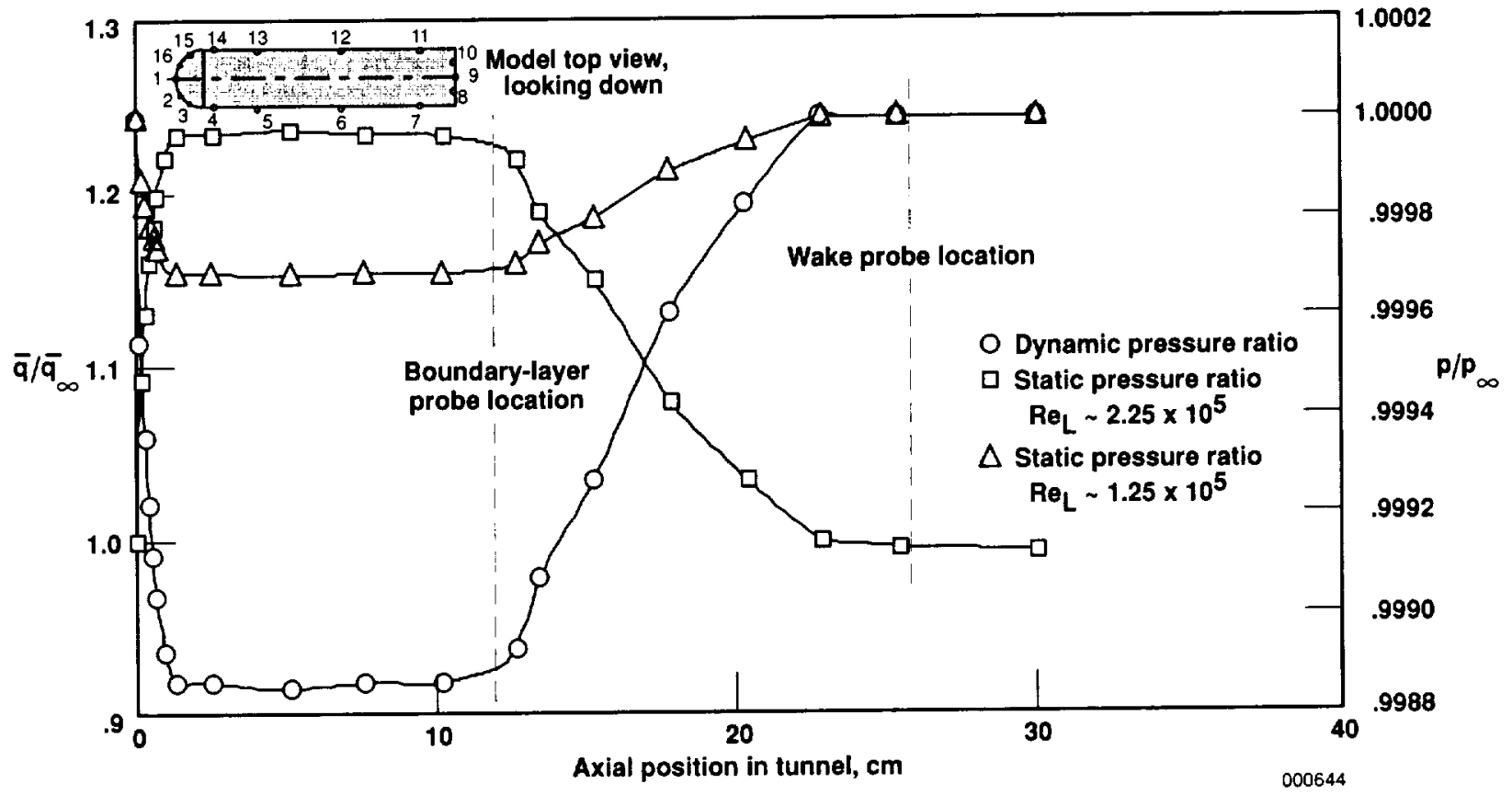

Figure 8. Dynamic pressure calibration to account for tunnel blockage.

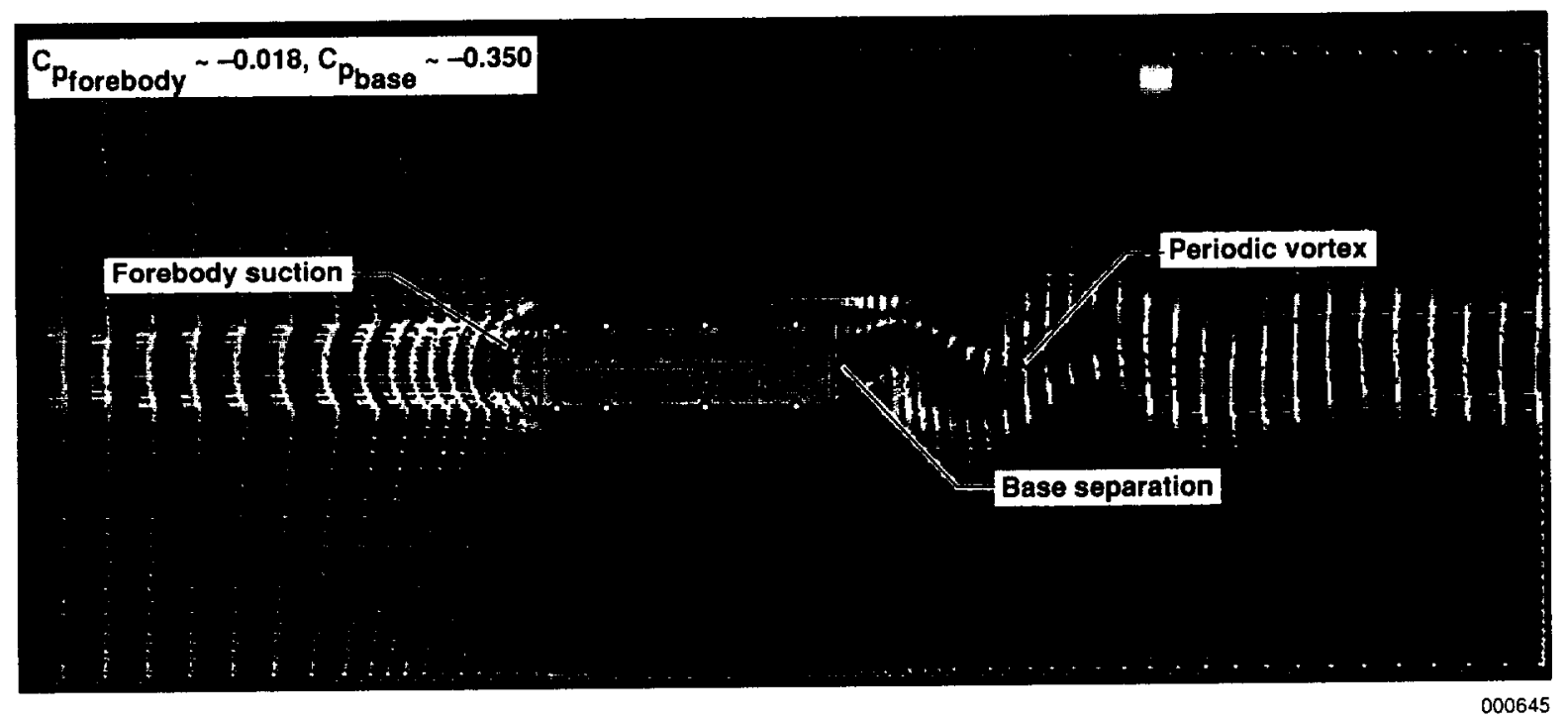

Figure 9. Two-dimensional, incompressible CFD solutions of wind-tunnel model flow field (smooth configuration). 


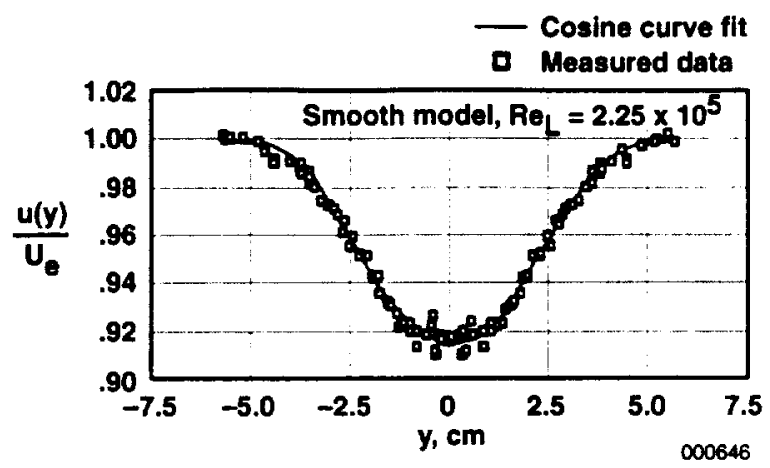

Figure 10. Example wind-tunnel wake data.

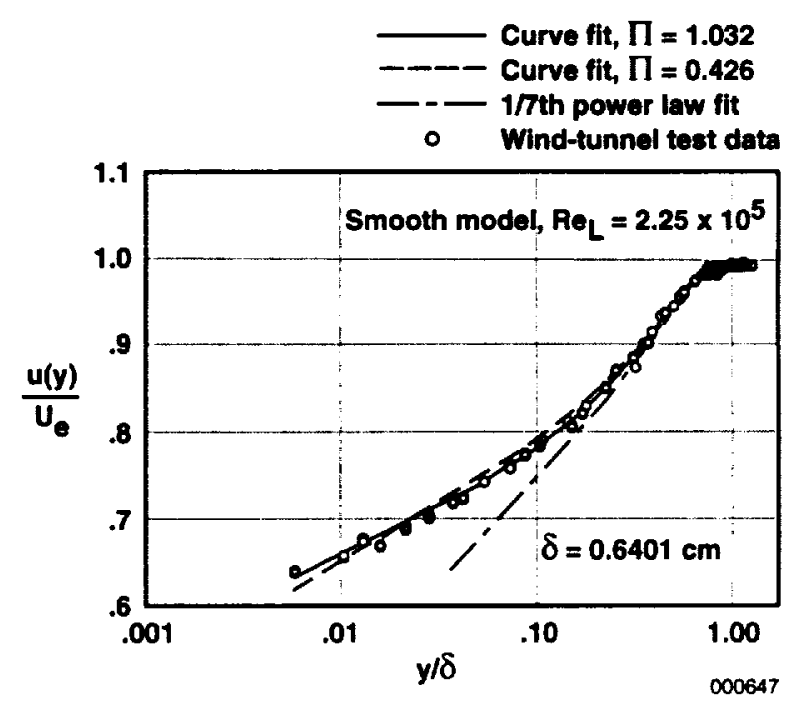

Figure 11. Example wind-tunnel boundary-layer curve fit. 


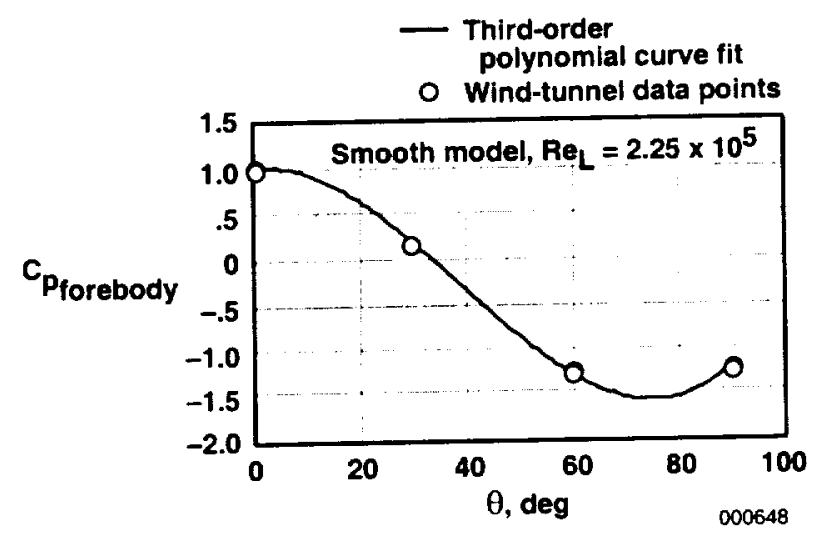

Figure 12. Example forebody pressure coefficient curve fit.

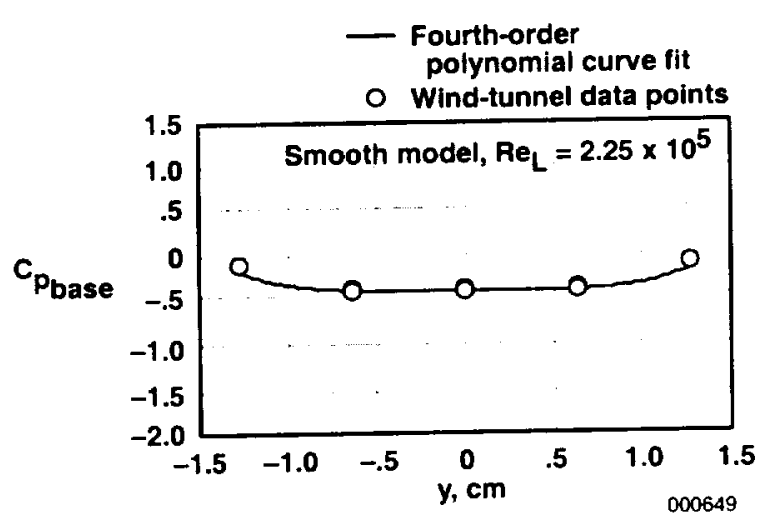

Figure 13. Example base pressure coefficient curve fit. 


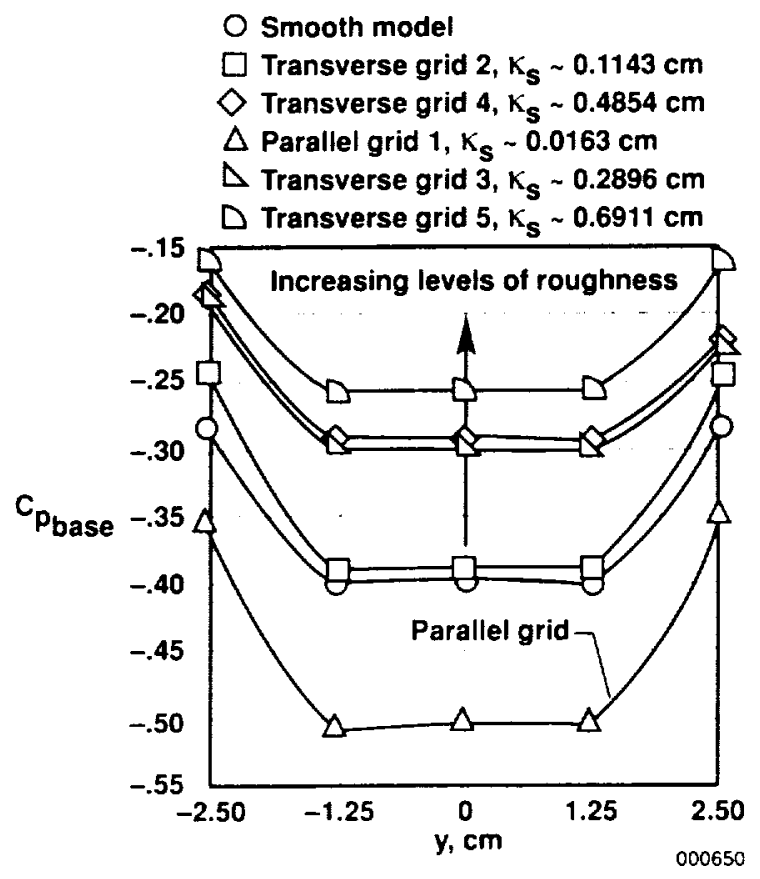

(a) $\mathrm{Re}_{L}=2.25 \times 10^{5}$.

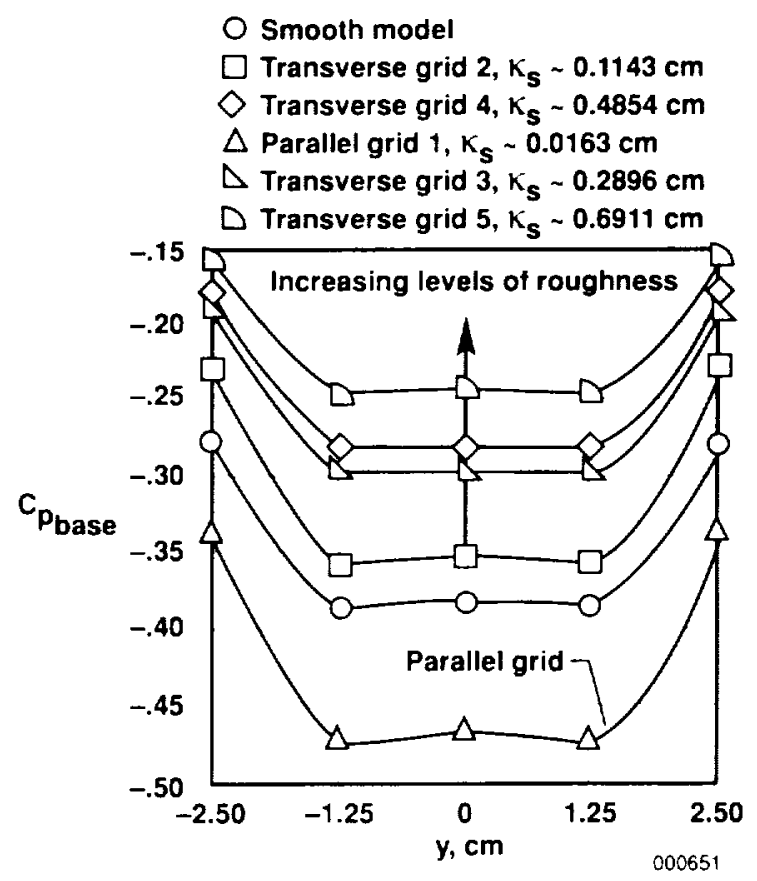

(b) $\mathrm{Re}_{L}=1.25 \times 10^{5}$.

Figure 14. Base pressure distributions for various grid patterns. 


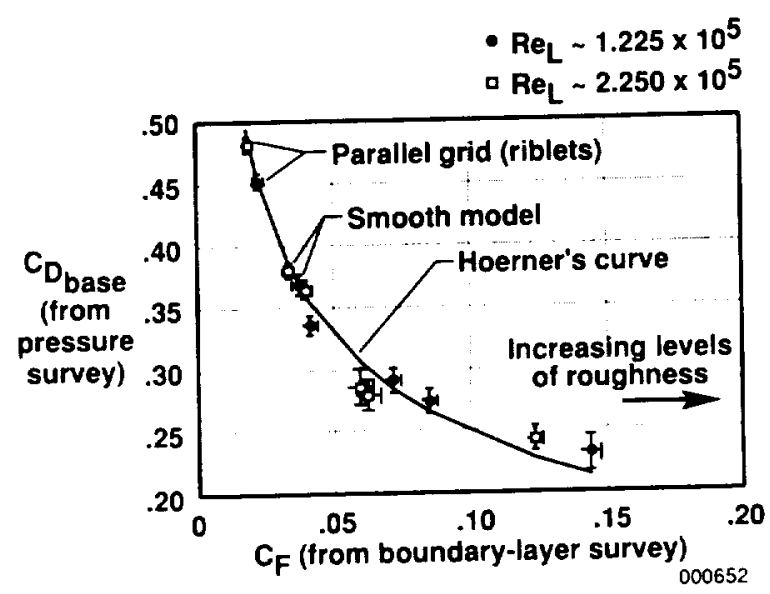

Figure 15. Comparison of wind-tunnel base drag data as a function of Hoerner's curve.

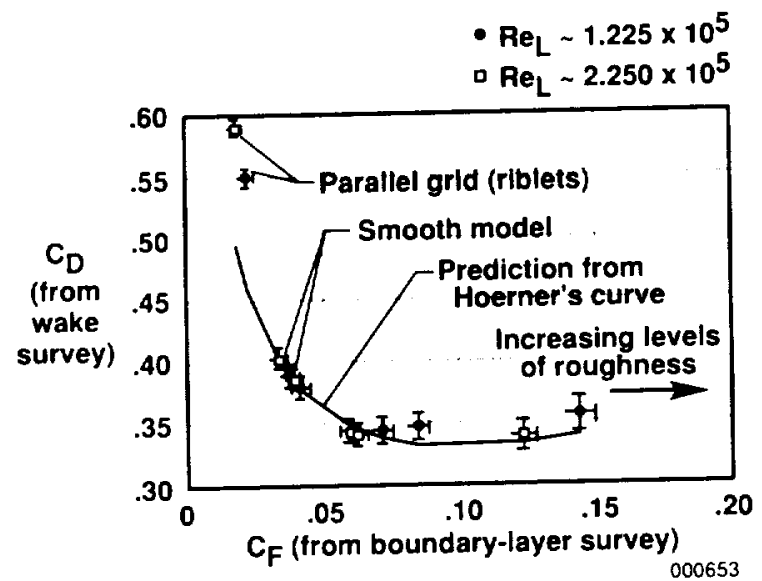

Figure 16. Comparison of wind-tunnel wake survey data as a function of the predicted "drag bucket." 


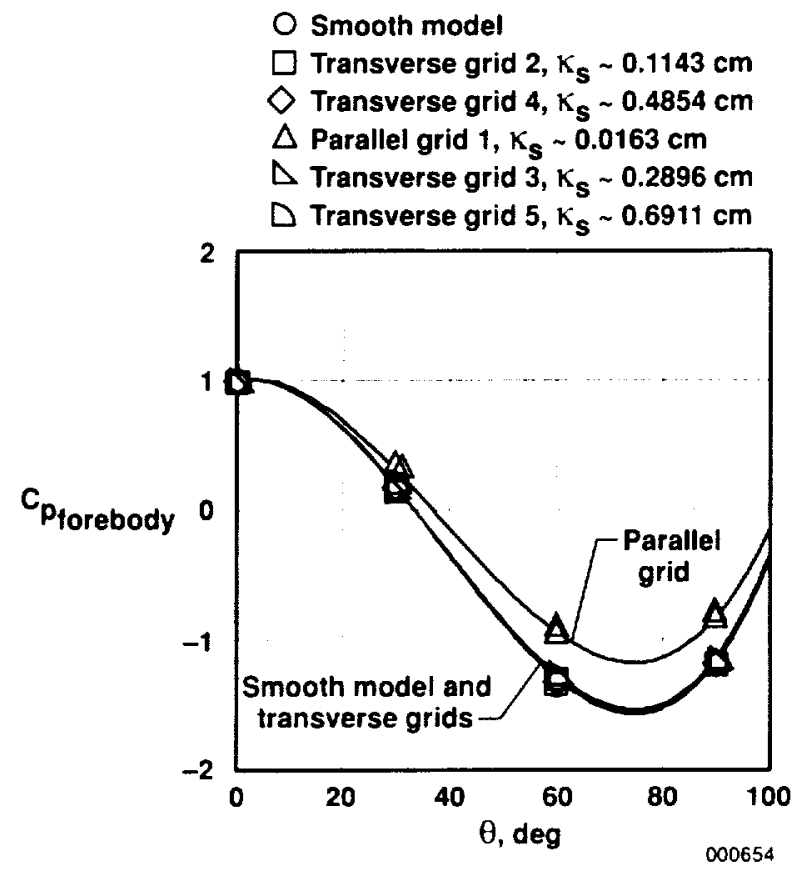

(a) $\operatorname{Re}_{L}=2.25 \times 10^{5}$.

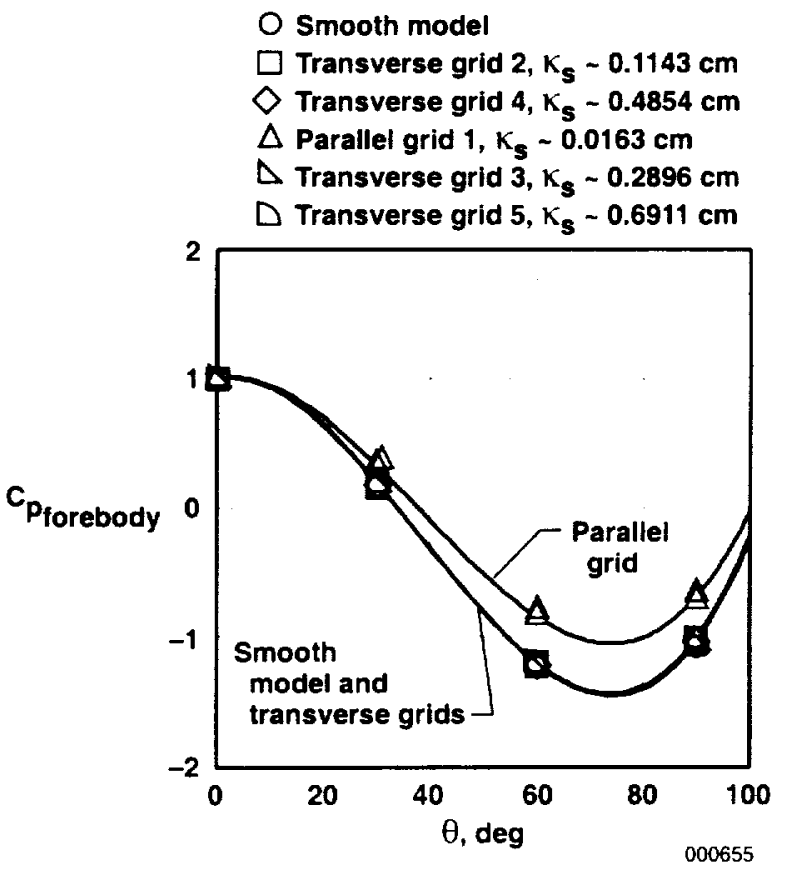

(b) $\mathrm{Re}_{L}=1.25 \times 10^{5}$.

Figure 17. Forebody pressure distributions for various grid patterns. 


\section{APPENDIX ERROR ANALYSIS METHODS}

\section{Introduction}

An approximate accounting of overall error in the wind tunnel-derived drag coefficient estimates is derived herein. The wake error analysis is presented first; the boundary-layer skin-friction error analysis is presented next. The estimated errors in the forebody and base pressure drag coefficients are presented last. The error equations derived in this appendix were used to calculate the data point error bounds plotted in figures 15 and 16.

\section{Estimating the Wake Drag Coefficient Errors}

An approximate accounting of overall error in the wake drag coefficient can be performed using a linear perturbation analysis. Using the fundamental definition for momentum thickness, linear perturbations can be expressed in terms of the velocity profile curve-fit error $\Delta\left[\frac{\hat{u}(y)}{U_{e}}\right]$ by taking the first variation of the forebody surface incidence angle, $\theta$, with respect to $u(y) / U_{e}$ :

$$
\begin{aligned}
& \Delta \theta=\Delta_{u(y)} / U_{e}\left[\int_{-\delta}^{\delta}\left[\frac{u(y)}{U_{e}}\right]\left[1-\frac{u(y)}{U_{e}}\right] d y\right] \\
& =\delta \int_{-1}^{1}\left[\frac{\Delta_{\hat{u}(\xi)}}{U_{e}}\left[1-2 \frac{u(\xi)}{U_{e}}\right]\right] d \xi
\end{aligned}
$$

The mean-square error in momentum thickness is evaluated by taking the expectation of the square of equation (A-1).

$$
\begin{aligned}
& \Psi_{\Delta \theta_{w}} \\
& =\mathrm{E}\left[\Delta \theta^{2}\right] \\
& =\delta^{2} \mathrm{E}\left[\int_{-1}^{1}\left\{\Delta \frac{\hat{u} \xi}{U_{e}}\left[1-2\left[\frac{\hat{u}(\zeta)}{U_{e}}\right]\right]\right\} d \xi\right. \\
& \left.\quad \times \int_{-1}^{1}\left\{\Delta \frac{\hat{u}(\zeta)}{U_{e}}\left[1-2\left[\frac{\hat{u}(\zeta)}{U_{e}}\right]\right]\right\} d \zeta\right] \\
& \quad \times \delta^{2} \int_{-1}^{1} \int_{-1}^{1} \mathrm{E}\left[\Delta \frac{\hat{u}(\xi)}{U_{e}} \Delta \frac{\hat{u}(\zeta)}{U_{e}}\right]\left\{\left[1-2\left[\frac{\hat{u}(\xi)}{U_{e}}\right]\right]\right\} \\
& \quad \times\left\{\left[1-2\left[\frac{\hat{u}(\zeta)}{U_{e}}\right]\right]\right\} d \zeta d \xi
\end{aligned}
$$

Assuming that random local errors in the velocity profile curve fit are uncorrelated, the expectation operation in equation ( $\mathrm{A}-2)$ becomes

$$
\begin{aligned}
& \mathrm{E}\left[\Delta \frac{\hat{u}(\xi)}{U_{e}} \Delta \frac{\hat{u}(\zeta)}{U_{e}}\right] \\
& \quad=\left\{\begin{array}{c}
0 \text { when } \xi \neq \zeta \\
\Psi_{\Delta u / U_{e}}^{2} \text { when } \xi=\zeta
\end{array}\right\} \\
& =\Psi_{\Delta u / U_{e}\left[\Lambda_{\xi . \zeta}\right]}^{2}
\end{aligned}
$$

In equation (A-3), $\Lambda_{\xi, \zeta}$ is the Dirac delta function ${ }^{16}$ and $\Psi_{\Delta u / U_{e}}^{2}$ is the mean-square error in the velocity distribution curve fit. Substituting equation (A-3) into equation (A-2), the interior integral reduces to the following:

$$
\begin{aligned}
& \int_{-1}^{l} \mathrm{E}\left[\Delta \frac{\hat{u}(\xi)}{U_{e}} \Delta \frac{\hat{u}(\zeta)}{U_{e}}\right]\left\{\left[1-2\left[\frac{\hat{u}(\xi)}{U_{e}}\right]\right]\right\} \\
& \left\{\left[1-2\left[\frac{\hat{u}(\zeta)}{U_{e}}\right]\right]\right\} d \zeta \\
& =\Psi_{\Delta u}^{2} / U_{e}\left[1-2\left[\frac{\hat{u}(\zeta)}{U_{e}}\right]\right]^{2}
\end{aligned}
$$

Substituting equation (A-4) into equation (A-2), and using the wake cosine law (eq. (2)) to evaluate the outer 
integral, the approximate mean-square error in the momentum thickness reduces to the following:

$\Psi_{\Delta \theta_{w}}^{2}=\delta^{2} \Psi_{\Delta u / U_{e}}^{2}\left[3\left[\frac{u_{\min }}{U_{e}}\right]^{2}-2\left[\frac{u_{\min }}{U_{e}}\right]+1\right](\mathrm{A}-5)$

A first-order perturbation of equation (A-5) gives the error equation for the free-stream momentum thickness estimate (assuming that errors in the velocity ratio and shape parameter are negligible when compared to the momentum thickness errors):

$$
\begin{aligned}
\Psi_{\Delta \theta_{\infty}}^{2}= & \Psi_{\Delta \theta_{u}}^{2}\left[\frac{U_{e}}{U_{\infty}}\right]^{|H+5|} \\
= & \delta^{2} \Psi_{\Delta u / U_{r^{\prime}}}^{2}\left[\frac{U_{e}}{U_{\infty}}\right]^{|H+5|} \\
& \times\left[3\left[\frac{{ }^{\prime \prime} \min }{U_{e}}\right]^{2}-2\left[\frac{U_{\min }}{U_{e}}\right]+1\right]
\end{aligned}
$$

Finally. the approximate mean square error in total drag coefficient is

$$
\begin{aligned}
& \Psi^{2} C_{D_{0}} \\
& =4 \frac{\Psi^{2} \Delta \theta_{\infty}}{h_{\text {base }}^{2}} \\
& =4 \frac{\delta^{2} \Psi_{\Delta u}^{2} U_{i}}{h_{\text {base }}}\left[\frac{U_{e}}{U_{\infty}}\right]^{\mid H+51} \\
& \quad \times\left[3\left[\frac{{ }_{\text {min }}}{U_{e^{\prime}}}\right]^{2}-2\left[\frac{u_{\text {min }}}{U_{t^{\prime}}}\right]+1\right]
\end{aligned}
$$

In equation (20), $H$ is the shape parameter defined by equation (10), $\delta$ is the boundary-layer thickness, and $\Psi_{\Delta w / U^{2}}^{2}$ is the mean-square error in the velocity profile curve fit.

Estimating the Forebody Viscous Drag

$$
\text { Coefficient Errors }
$$

The boundary-layer error analysis follows a nearly identical process when compared to the wake error analysis. The main exceptions are that the integrals are performed from $\{0, \delta\}$ instead of $\{-\delta, \delta\}$, and the velocity distribution is given by the law of the wake instead of the cosine law velocity distribution. Keeping these differences in mind, the mean-squared error formula for the momentum thickness becomes

$$
\begin{aligned}
& \Psi_{\Delta \theta_{w}}^{2} \\
& =\mathbf{E}\left|\Delta \theta^{2}\right| \\
& =\delta^{2} \\
& \mathrm{E}\left[\int_{0}^{1}\left\{\Delta \frac{\hat{u}(\xi)}{U_{e}}\left[1-2\left[\frac{\hat{u}(\xi)}{U_{e}}\right]\right]\right\} d \xi \int_{0}^{1}\left\{\Delta \frac{\hat{u}(\zeta)}{U_{e}}\left[1-2\left[\frac{\hat{u}(\zeta)}{U_{e}}\right]\right]\right\} d \zeta\right]
\end{aligned}
$$

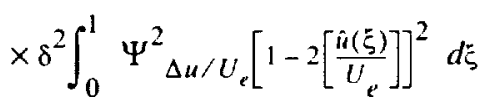

Substituting the law-of-the-wake velocity distribution (eq. (16)) into equation (A-8) and integrating gives the mean-square error in momentum thickness:

$$
\begin{aligned}
& \Psi^{2} \Delta \theta \\
& =\frac{\delta^{2} \Psi^{2} \Delta u / U}{\kappa^{2}} \\
& \quad \times\left[\pi \kappa^{2}-2 \sqrt{2 f_{x}}|\pi+4 \Pi| \kappa+4 f_{x}\left|\pi+5.48304 \Pi+\pi \Pi^{2}\right|\right]
\end{aligned}
$$

The corresponding mean-square error in the viscous forebody drag coefficient estimate is

$$
\begin{aligned}
& \Psi^{2} C_{F} \\
& =\left[\frac{2}{L} \frac{H}{|H+(2+H) \beta|}\right]^{2} \\
& \times \frac{\delta^{2} \Psi^{2} \Delta u / U}{\pi \kappa^{2}} \\
& \times\left[\pi k^{2}-2 \sqrt{2 c_{x}}|\pi+4 \Gamma 1| \kappa+4 f_{x}\left[\pi+5.48304 \Gamma I+\pi \Pi^{2}\right]\right]
\end{aligned}
$$

\section{Estimating the Forebody Drag Coefficient}




$$
\mu_{\theta}=\frac{\sum_{i=1}^{N_{\text {trials }}} C_{p_{i}}(\theta)}{N_{\text {trials }}}
$$

and

$$
\sigma_{\theta}^{2}=\frac{\sum_{i=1}^{N_{\text {rrials }}}\left[C_{p_{i}}(\theta)-\mu_{\theta}\right]^{2}}{N_{\text {trials }}-1}
$$

Based on equation (30), which is a pressure integral weighted by the cosine of the local incidence angle, mean-square error in forebody drag coefficient is computed as the sum-square of individual forebody pressure coefficient errors, weighted by the cosine of the local incidence angle.

$$
\Psi^{2} C_{D_{\text {forebody }}}=\sum_{i=1}^{7}\left[\sigma_{\theta} \cos \theta^{2}\right]
$$

\section{Estimating the Base Drag Coefficient Errors}

The base drag coefficient errors are computed in a similar manner as the forebody drag coefficient errors. However, instead of weighting the $C_{p}$ standard deviations using $\cos [\theta]$, the weighting procedure follows the scheme used to establish the base area curve fits (that is, the $C_{p}$ variances in the two ports along the sides of the model are weighted one-half as much as the $C_{p}$ variances in the three base-area ports):

$$
\Psi_{C_{D_{\text {huse }}}^{2}}^{2}=\frac{\sum_{i=1}^{2}\left[\frac{1}{2} \sigma_{\text {side }_{i}}{ }^{2}\right]+\sum_{i=1}^{3}\left[\sigma_{\text {base }_{i}}{ }^{2}\right]}{4}
$$




\section{$\underline{\text { References }}$}

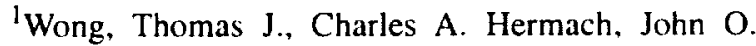
Reller, Jr., and Bruce E. Tinling, "Preliminary Studies of Manned Satellites-Wingless Configurations: Lifting Body," NACA Conference on High-Speed Aerodynamics: A Compilation of the Papers Presented, NASA TM-X-67369, 1958, pp. 35-44.

${ }^{2}$ Hoerner, Sighard F., Fluid-Dynamic Drag: Practical Information on Aerodynamic Drag and Hydrodynamic Resistance, Self-published work, Library of Congress Card Number 64-19666, Washington, D.C., 1965.

${ }^{3}$ Tanner, M., "Theories for Base Pressure in Incompressible Steady Base Flow," Progress in Aerospace Sciences, vol. 34, 1998, pp. 423-480.

${ }^{4}$ Rathakrishnan, E., "Effect of Splitter Plate on Bluff Body Drag," AIAA Journal, vol. 37, no. 9, Sept. 1999. pp. 1125-1126.

${ }^{5}$ Saltzman, Edwin J., K. Charles Wang, and Kenneth W. Iliff, "Flight-Determined Subsonic Lift and Drag Characteristics of Seven Lifting-Body and Wing-Body Reentry Vehicle Configurations With Truncated Bases," AIAA-99-0383, Jan. 1999.

${ }^{6}$ Whitmore, Stephen A. and Timothy R. Moes, "A Base Drag Reduction Experiment on the X-33 Linear Aerospike SR-71 Experiment (LASRE) Flight Program," AIAA-99-0277, Jan. 1999.

${ }^{7}$ Mills, Anthony F., Heat and Mass Transfer, Irwin Publishing Co., Burr Ridge, IL, 1995.

${ }^{8}$ Adaptive Research, CFD 2000: Computational Fluid Dynamics System Version 2.2 User's Mamual, Pacific-Sierra Research Corporation, 1995.
${ }^{9}$ Rade, Lennart and Bertil Westergren, Beta Mathematics Handbook: Concepts, Theorems, Methods, Algorithms, Formulas, Graphs, Tables, 2nd ed., CRC Press, Boca Raton, FL, 1990.

10White, Frank M, Viscous Fluid Flow, 2nd ed., McGraw-Hill, New York, 1991.

"Coles, Donald, "The Law of the Wake in the Turbulent Boundary Layer," Journal of Fluid Mechanics, vol. 1, 1955, pp. 191-226.

${ }^{12}$ Whitmore, Stephen A., Marco Hurtado, Jose Rivera, and Jonathan W. Naughton, "A Real-Time Method for Estimating Viscous Forebody Drag Coefficients," AIAA-2000-0781, Jan. 2000 (also available as NASA TM-2000-209015).

${ }^{13}$ Clauser, Francis H., "Turbulent Boundary Layers in Adverse Pressure Gradients," Journal of Aeronautical Sciences, vol. 21, no. 2, Jan. 1954, pp. 91-108.

${ }^{14}$ Krishnan, V., P. R. Viswanath, and S. Rudrakumar, "Effects of Riblets on Axisymmetric Base Pressure," Journal of Spacecraft and Rockets, vol. 34, no. 2 , March-April 1997, pp. 256-258.

${ }^{15}$ Walsh, Michael J., "Riblets as a Viscous Drag Reduction Technique," AlAA Jourmal, vol. 21, no. 4 , Apr. 1983, pp. 485-486.

${ }^{16}$ Freiberger, W. F., ed., The International Dictionary of Applied Mathematics, Van Nostrand Company, Inc., Princeton, NJ, 1960. 


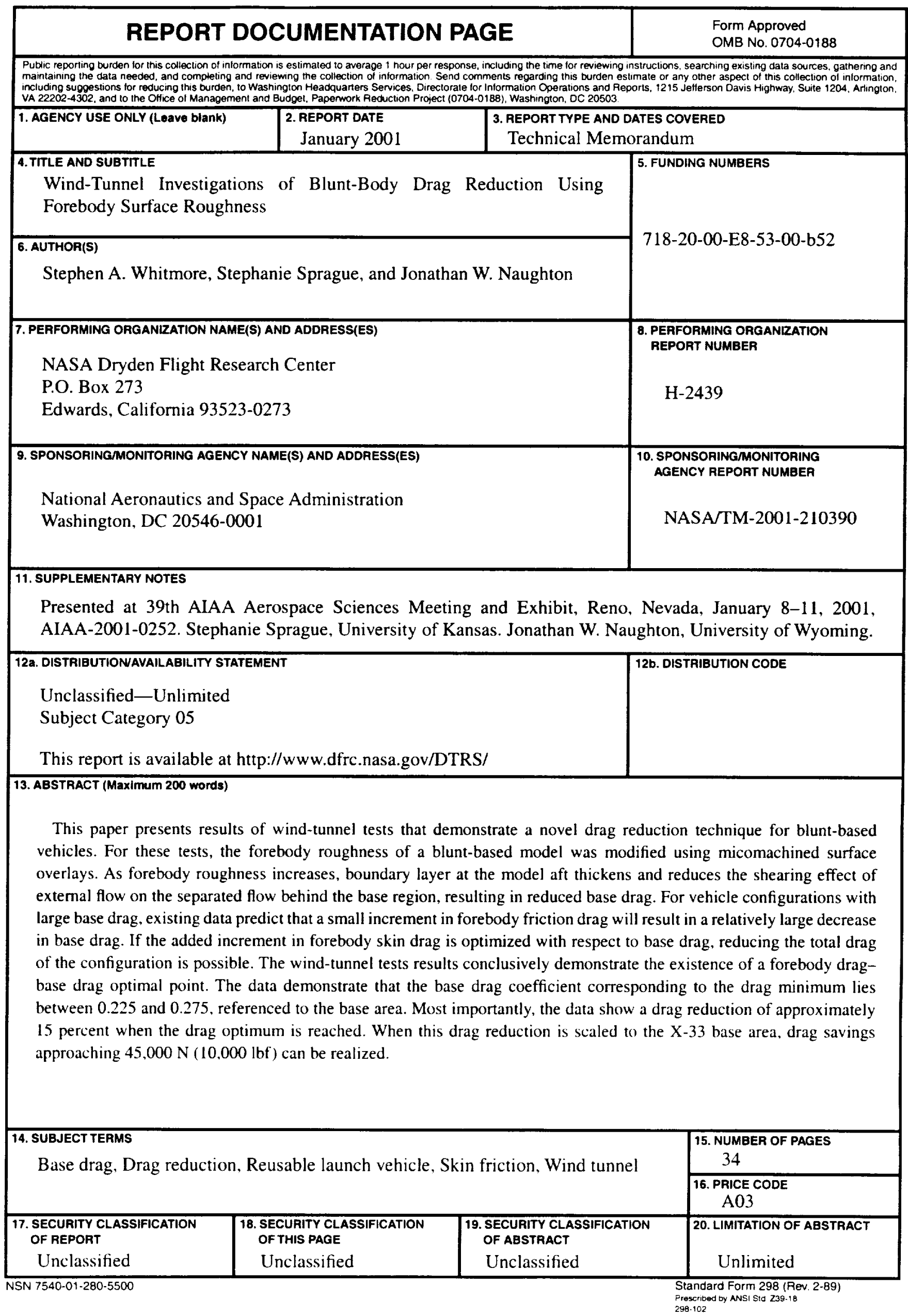



National Aeronautics and

Space Administration

Code JTT

Washington, D.C. 20546-0001

USA

Official Business

Penalty for Private Use, $\$ 300$
SPECIAL FOURTH-CLASS RATE POSTAGE AND FEES PAID

NASA

PERMIT No G27

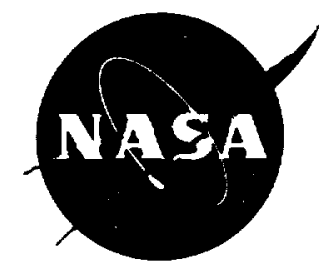

POSTMASTER: If Undeliverable (Section 158

Postal manual) Do Not Return 